\title{
Long-term analysis of carbon dioxide and methane column-averaged mole fractions retrieved from SCIAMACHY
}

\author{
O. Schneising, M. Buchwitz, M. Reuter, J. Heymann, H. Bovensmann, and J. P. Burrows \\ Institute of Environmental Physics (IUP), University of Bremen FB1, Bremen, Germany \\ Received: 22 September 2010 - Published in Atmos. Chem. Phys. Discuss.: 11 November 2010 \\ Revised: 23 March 2011 - Accepted: 24 March 2011 - Published: 28 March 2011
}

\begin{abstract}
Carbon dioxide $\left(\mathrm{CO}_{2}\right)$ and methane $\left(\mathrm{CH}_{4}\right)$ are the two most important anthropogenic greenhouse gases contributing to global climate change. SCIAMACHY onboard ENVISAT (launch 2002) was the first and is now with TANSO onboard GOSAT (launch 2009) one of only two satellite instruments currently in space whose measurements are sensitive to $\mathrm{CO}_{2}$ and $\mathrm{CH}_{4}$ concentration changes in the lowest atmospheric layers where the variability due to sources and sinks is largest.

We present long-term SCIAMACHY retrievals (20032009) of column-averaged dry air mole fractions of both gases (denoted $\mathrm{XCO}_{2}$ and $\mathrm{XCH}_{4}$ ) derived from absorption bands in the near-infrared/shortwave-infrared (NIR/SWIR) spectral region focusing on large-scale features. The results are obtained using an upgraded version (v2) of the retrieval algorithm WFM-DOAS including several improvements, while simultaneously maintaining its high processing speed. The retrieved mole fractions are compared to global model simulations (CarbonTracker $\mathrm{XCO}_{2}$ and TM5 $\mathrm{XCH}_{4}$ ) being optimised by assimilating highly accurate surface measurements from the NOAA/ESRL network and taking the SCIAMACHY averaging kernels into account. The comparisons address seasonal variations and long-term characteristics.
\end{abstract}

The steady increase of atmospheric carbon dioxide primarily caused by the burning of fossil fuels can be clearly observed with SCIAMACHY globally. The retrieved global annual mean $\mathrm{XCO}_{2}$ increase agrees with CarbonTracker within the error bars $\left(1.80 \pm 0.13 \mathrm{ppm} \mathrm{yr}^{-1}\right.$ compared to $1.81 \pm 0.09 \mathrm{ppm} \mathrm{yr}^{-1}$ ). The amplitude of the $\mathrm{XCO}_{2}$ seasonal cycle as retrieved by SCIAMACHY, which is $4.3 \pm 0.2 \mathrm{ppm}$ for the Northern Hemisphere and $1.4 \pm 0.2 \mathrm{ppm}$ for the South-

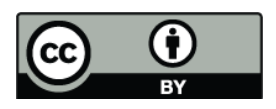

Correspondence to: O. Schneising (oliver.schneising@iup.physik.uni-bremen.de) ern Hemisphere, is on average about $1 \mathrm{ppm}$ larger than for CarbonTracker.

An investigation of the boreal forest carbon uptake during the growing season via the analysis of longitudinal gradients shows good agreement between SCIAMACHY and CarbonTracker concerning the overall magnitude of the gradients and their annual variations. The analysis includes a discussion of the relative uptake strengths of the Russian and North American boreal forest regions.

The retrieved $\mathrm{XCH}_{4}$ results show that after years of stability, atmospheric methane has started to rise again in recent years which is consistent with surface measurements. The largest increase is observed for the tropics and northern midand high-latitudes amounting to about $7.5 \pm 1.5 \mathrm{ppb} \mathrm{yr}^{-1}$ since 2007. Due care has been exercised to minimise the influence of detector degradation on the quantitative estimate of this anomaly.

\section{Introduction}

The atmospheric concentrations of the two most important anthropogenic greenhouse gases carbon dioxide $\left(\mathrm{CO}_{2}\right)$ and methane $\left(\mathrm{CH}_{4}\right)$ have increased significantly since the start of the Industrial Revolution and are now about $40 \%$ and $150 \%$, respectively, higher compared to the pre-industrial levels (Solomon et al., 2007). While carbon dioxide concentrations have risen steadily during the last decades, atmospheric methane levels were rather stable from 1999 to 2006 (Bousquet et al., 2006) before a renewed growth was observed from surface measurements since 2007 (Rigby et al., 2008; Dlugokencky et al., 2009). Further increase of both gases is expected to result in a warmer climate with adverse consequences, such as rising sea levels and an increase of extreme weather conditions. A reliable prediction requires an accurate understanding of the sources and sinks of the greenhouse gases. Unfortunately, this

Published by Copernicus Publications on behalf of the European Geosciences Union. 
is limited by the sparse ground-based measurements with a lack of high-frequency surface observations in continental regions particularly outside North America and Europe resulting in large uncertainties (see, e.g., Stephens et al., 2007). However, satellite data, if accurate and precise enough, have the potential to significantly reduce surface flux uncertainties (Rayner and O'Brien, 2001; Houweling et al., 2004) by deducing strength and spatiotemporal distribution of the sources and sinks via inverse modelling which is based on fitting the model emissions to the satellite observations. High reduction of regional flux uncertainties additionally requires high sensitivity to near-surface greenhouse gas concentration changes because the variability due to regional sources and sinks is largest in the lowest atmospheric layers. Sensitivity to all altitude levels, including the boundary layer, can be achieved using reflected solar radiation in the near-infrared/shortwave-infrared (NIR/SWIR) spectral region, whereas measurements of emissions in the thermal infrared (TIR) available from, e.g., HIRS/TOVS (Chédin et al., 2002, 2003), AIRS (Engelen et al., 2004; Engelen and McNally, 2005; Aumann et al., 2005; Strow et al., 2006; Maddy et al., 2008), IASI (Crevoisier et al., 2009a,b), and TES (Kulawik et al., 2010) are primarily sensitive to middle to upper tropospheric greenhouse gas concentrations. SCIAMACHY onboard ENVISAT (launch 2002) was the first and is now with TANSO onboard GOSAT (launch 2009) (Yokota et al., 2009) one of only two satellite instruments currently in space which can benefit in this way from NIR/SWIR nadir measurements. Both instruments cover important absorption bands of both gases in this spectral range. Therefore, SCIAMACHY plays a pioneering role in the relatively new area of greenhouse gas observations from space (Buchwitz et al., 2005a,b, 2006, 2007; Schneising et al., 2008, 2009; Houweling et al., 2005; Bösch et al., 2006; Barkley et al., 2006a,c,b, 2007; Frankenberg et al., 2005, 2006, 2008a,b). In the case of methane, SCIAMACHY data have already been incorporated in the modelling of emissions (Bergamaschi et al., 2007, 2009; Bloom et al., 2010).

In this manuscript, long-term global carbon dioxide and methane dry air column-averaged mole fraction data sets from SCIAMACHY derived using Weighting Function Modified DOAS (WFM-DOAS) developed at the University of Bremen are presented and discussed focusing on a comparison of their long-term behaviour and seasonal variation with model simulations. The analysis constitutes seven years (2003-2009) of greenhouse gas information derived from European Earth observation data improving and extending pre-existing WFM-DOAS retrievals (Schneising et al., 2008, 2009). Recently, another SCIAMACHY multi-year methane data set has been generated independently (Frankenberg et al., 2011).

This manuscript is organised as follows: in Sect. 2 the SCIAMACHY instrument and its measurement principle are introduced and explained. This is followed by a short description of the improved WFM-DOAS retrieval algorithm in Sect. 3 focusing on the changes compared to the previous version. The new SCIAMACHY long-term carbon dioxide and methane data sets are discussed in Sect. 4 and conclusions are given in Sect. 5 .

\section{The SCIAMACHY instrument}

SCIAMACHY, which is a multi-national (Germany, The Netherlands, Belgium) contribution to the European environmental satellite ENVISAT, is a grating spectrometer that measures reflected, backscattered and transmitted solar radiation at moderate spectral resolution (0.2-1.4 nm) (Burrows et al., 1990, 1995; Burrows and Chance, 1991; Bovensmann et al., 1999). The spectral region from $214 \mathrm{~nm}$ to $1750 \mathrm{~nm}$ is measured in six adjacent channels, and there are two additional channels covering the regions 1940-2040 and 2265$2380 \mathrm{~nm}$. Each spectral channel comprises a grating focusing optics and a 1024 element monolithic diode array. In addition, SCIAMACHY has 7 broad band channels, the Polarisation Measurement Devices (PMD), which monitor the upwelling radiation polarised with respect to the instrument plane at high spatial resolution providing sub-pixel information.

ENVISAT was launched into a sun-synchronous orbit in descending node having an equator crossing time of 10:00 a.m. local time. During every orbit calibration measurements are made during the eclipse, followed by a solar occultation and limb atmospheric measurement. On the Earth's day side SCIAMACHY performs alternate nadir and limb observations. These measurements can be inverted to obtain a large number of atmospheric data products (Bovensmann et al., 1999) including the column amounts of $\mathrm{CH}_{4}, \mathrm{CO}_{2}$ and $\mathrm{O}_{2}$ which are relevant for this study. As a result of SCIAMACHY's observation of greenhouse gas overtone absorptions in the near-infrared/shortwave infrared (NIR/SWIR) solar backscattered spectrum, SCIAMACHY yields the vertical columns of $\mathrm{CO}_{2}$ and $\mathrm{CH}_{4}$ with high sensitivity down to the Earth's surface (Buchwitz et al., 2005a). As the integration time for the detectors is optimised around an orbit, the horizontal resolution of the nadir measurements depends on orbital position and spectral interval, but is typically $60 \mathrm{~km}$ across track by $30 \mathrm{~km}$ along track for the spectral fitting windows used in this study.

Overall, the in-flight optical performance of SCIAMACHY is very similar to that predicted from the pre-flight on ground characterisation and calibration activities. There is, however, a time dependent optical throughput variation in the SCIAMACHY NIR/SWIR channel 7, which has many resolved $\mathrm{CO}_{2}$ absorption features, and channel 8, which was designated to be the main $\mathrm{CH}_{4}$ channel. This results from the in-flight deposition of ice on the detectors. As ice absorbs and scatters at these wavelengths, this adversely affects the trace gas retrievals by reducing the signal to noise and changing the instrument slit function (Gloudemans et al., 
2005; Buchwitz et al., 2005b). The WFM-DOAS results presented in this manuscript have been derived using $\mathrm{CO}_{2}$ and $\mathrm{CH}_{4}$ absorption features in channel $6(1000-1750 \mathrm{~nm})$ and the $\mathrm{O}_{2}$ A-band absorption in channel $4(605-805 \mathrm{~nm})$ which are not affected by an ice-layer as their detectors operate at higher temperatures. However, channel $6+$ which is used for the methane retrievals suffers from an increasing number of dead and bad detector pixels including so-called random telegraph detector pixels which unpredictably jump between at least two quasi-stable dark signal levels (Lichtenberg et al., 2006; Frankenberg et al., 2011).

\section{WFM-DOAS retrieval algorithm}

The retrieval of a long-lived and therefore relatively wellmixed gas such as carbon dioxide or methane is challenging as only the small variations on top of a large background yield information on its surface sources and sinks. Therefore, the retrieval algorithm has to meet the conflicting requirements of accuracy and speed in order to process the large amounts of data produced by SCIAMACHY. This is achieved by the WFM-DOAS retrieval technique (Buchwitz et al., 2000, 2005a,b; Buchwitz and Burrows, 2004) developed at the University of Bremen for the retrieval of trace gases and optimised for $\mathrm{CO}_{2}, \mathrm{CH}_{4}$ and $\mathrm{O}_{2}$ retrievals using a fast look-up table (LUT) scheme to avoid computationally expensive online radiative transfer calculations. The algorithm has been described in detail elsewhere (Buchwitz et al., 2000, 2005a,b; Buchwitz and Burrows, 2004; Schneising et al., 2008, 2009). We therefore focus on a discussion of the main differences between the current versions 2.0 and 2.1, which have been used to generate the data sets discussed in this manuscript, and the previous version 1.0 (Schneising et al., 2008, 2009). The version 2.1 differs from 2.0 in the additional usage of the SCIAMACHY M-factors in the Level 0$1 \mathrm{~b}$ processing to compensate for the radiometric degradation of the instrument (Bramstedt, 2008). An M-factor is defined as the ratio between a measured solar spectrum at time $t$ to a reference spectrum obtained for the same optical path at time $t_{0}$. The M-factors are multiplicative factors to the absolute radiometric calibration of SCIAMACHY.

\subsection{Retrieval of carbon dioxide mole fractions}

In order to convert the retrieved $\mathrm{CO}_{2}$ columns into columnaveraged mole fractions the $\mathrm{CO}_{2}$ columns are divided by the dry-air columns obtained from the simultaneously measured $\mathrm{O}_{2}$ columns obtained from the $\mathrm{O}_{2}$ A-band. The specific changes compared to WFMDv1.0 (Schneising et al., 2008) are:

- Use of spectra with improved calibration: Level 1 version 6 instead of version 5 including application of Mfactors in the Level $0-1 \mathrm{~b}$ processing.
- Use of improved spectroscopy: HITRAN 2008 (Rothman et al., 2009) instead of HITRAN 2004 (Rothman et al., 2005).

- Modified static detector pixel mask.

- Use of an improved look-up table scheme, i.e., use of an extended set of surface elevations $(0 \mathrm{~km}, 1 \mathrm{~km}, 2 \mathrm{~km}$, $3 \mathrm{~km}, 4 \mathrm{~km}, 5 \mathrm{~km})$ and albedos $(0.01,0.03,0.1,0.3,0.6$, 1.0) covering all naturally occurring surface types by means of interpolation.

- Use of a more realistic standard aerosol scenario in the forward model (OPAC background scenario described in Schneising et al., 2008, 2009).

- Processing of a longer time series: 2003-2009 instead of 2003-2005.

- Use of SCIAMACHY Absorbing Aerosol Index v4.1 (Tilstra et al., 2007) instead of EarthProbe/TOMS AAI (Herman et al., 1997) to filter strongly aerosol contaminated scenes, in particular desert dust storms.

- Change of full width at half maximum (FWHM) used for the $\mathrm{O}_{2}$ reference spectra calculation from $0.45 \mathrm{~nm}$ to $0.44 \mathrm{~nm}$ because of the associated improvement of fit quality. The effect of changing the $\mathrm{O}_{2}$ FWHM is a reduction in the retrieved column amount by about $0.5 \%$.

Due to small throughput losses of the detectors which are slowly increasing with time exhibiting different characteristics in the two spectral channels used for the $\mathrm{CO}_{2}$ (channel 6) and $\mathrm{O}_{2}$ (channel 4) column retrievals, the application of the SCIAMACHY M-factors to compensate for detector degradation ensures better $\mathrm{XCO}_{2}$ results concerning longterm behaviour, e.g., for the retrieved mean annual carbon dioxide growth rate. Without the consideration of the Mfactors the $\mathrm{XCO}_{2}$ growth rate would be biased low by a few tenths of $1 \mathrm{ppm}$. According to this conclusion, all carbon dioxide results presented in this manuscript are retrieved with WFMDv2.1. The seasonal cycle amplitude of the northern hemisphere is not affected by the M-factors, whereas the amplitude in the southern hemisphere is about $0.3 \mathrm{ppm}$ smaller when compensating for the radiometric degradation of the instrument.

The single ground pixel retrieval precision derived from averaging daily standard deviations of the retrieved $\mathrm{XCO}_{2}$ (Schneising et al., 2008) for 8 locations distributed around the globe provides a consistent estimate of the single measurement precision of about $6 \mathrm{ppm}$, respectively, which corresponds approximately to $1.5 \%$.

\subsection{Retrieval of methane mole fractions}

In order to convert the retrieved $\mathrm{CH}_{4}$ columns into columnaveraged mole fractions the $\mathrm{CH}_{4}$ columns are divided by the dry-air columns obtained from the simultaneously measured 


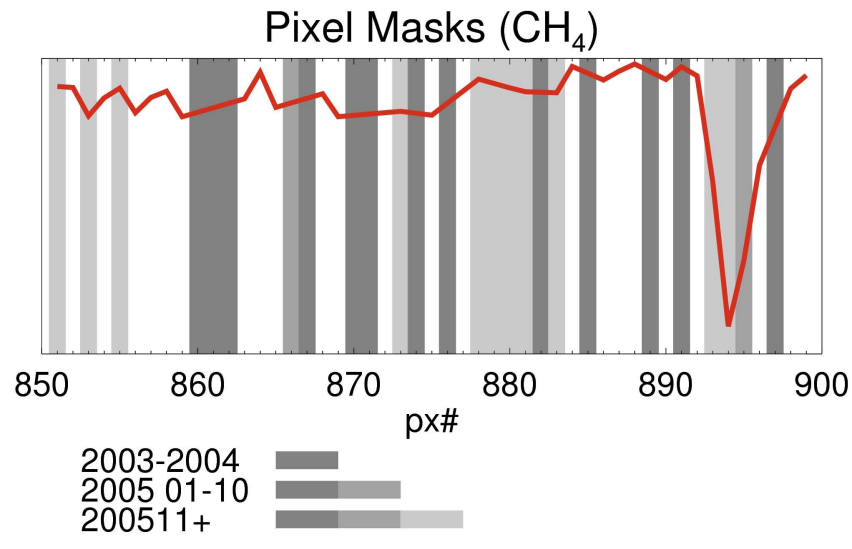

Fig. 1. Pixel masks used for the WFMDv2.0 methane retrieval. The red line shows the $\mathrm{CH}_{4}$ absorption and the shaded regions indicate bad pixels. Due to proceeding detector degradation in the spectral range used for the methane column retrieval three different time periods are used. Since November 2005 only one remaining detector pixel (\#896) in the Q-branch (the spectral region where the strongest absorption occurs) of the $2 v_{3}$ methane band is useable.

$\mathrm{CO}_{2}$ columns correcting for $\mathrm{CO}_{2}$ variability using CarbonTracker. $\mathrm{CO}_{2}$ is used as a proxy for the air column instead of $\mathrm{O}_{2}$ because of better cancellation of path length related retrieval errors. The specific changes compared to WFMDv1.0 (Schneising et al., 2009) are:

- Use of spectra with improved calibration: Level 1 version 6 instead of version 5 .

- Use of improved spectroscopy: HITRAN 2008 (Rothman et al., 2009) plus Jenouvrier et al., $2007 \mathrm{H}_{2} \mathrm{O}$ update in the methane fitting window instead of HITRAN 2004 (Rothman et al., 2005).

- Modified static detector pixel masks for three different time periods to get best possible results for the early years and stability until end of 2009 at the same time (see Fig. 1).

- Use of an improved look-up table scheme, i.e., use of an extended set of surface elevations $(0 \mathrm{~km}, 1 \mathrm{~km}, 2 \mathrm{~km}$, $3 \mathrm{~km}, 4 \mathrm{~km}, 5 \mathrm{~km})$ and albedos $(0.01,0.03,0.1,0.3,0.6$, $1.0)$ covering all naturally occurring surface types by means of interpolation.

- Use of a more realistic standard aerosol scenario in the forward model (OPAC background scenario described in Schneising et al., 2008, 2009).

- Processing of a longer time series: 2003-2009 instead of 2003-2005.

- Optimisation of filter criteria.
- Use of CarbonTracker version 2010 instead of 2007 (Peters et al., 2007, 2010) to correct the retrieved methane mole fractions for $\mathrm{CO}_{2}$ variability.

Due to proceeding detector degradation in the spectral range used for the methane column retrieval, static detector pixel masks for three different time periods (see Fig. 1) are used to get best possible results for the early years and stability until end of 2009 at the same time. Since November 2005 only one remaining detector pixel in the Q-branch of the $2 v_{3}$ methane band, which is the spectral region in the fitting window where the strongest absorption occurs, is useable. Therefore, the retrieval results since November 2005 are expected to be of reduced quality with regard to noise compared to the prior time period where more Q-branch detector pixels are available. Because of the increase of dead or bad pixels, the filter criteria have to be changed for data after October 2005 (third period) because the availability of considerably fewer detector pixels automatically increases the fit error. Therefore the filter criterion on the $\mathrm{CH}_{4}$ column fit error is relaxed for the third period to get a comparable amount of retrievals classified as good. The quality filtering for this period is additionally extended to restrict to land only scenes and to filter out cloud contaminated scenes with a threshold algorithm like in the case of $\mathrm{XCO}_{2}$ based on sub-pixel information provided by the SCIAMACHY Polarisation Measurement Device (PMD) channel A covering the spectral region $310-365 \mathrm{~nm}$ in the UV.

As the $\mathrm{CH}_{4}$ and $\mathrm{CO}_{2}$ columns used for the computation of the column-averaged mole fractions $\mathrm{XCH}_{4}$ are both retrieved from neighbouring fitting windows in the same channel, long-term throughput loss issues adversely affecting $\mathrm{XCH}_{4}$ (as in the case of $\mathrm{XCO}_{2}$ ) are only expected to a minor extent because potential effects on the column growth rates cancel out to first order when computing the $\mathrm{CH}_{4} / \mathrm{CO}_{2}$-ratio due to similar radiometric degradation in both windows. Therefore, and because of possible complications due to the relatively large number of dead or bad detector pixels in the methane fitting window, which could introduce additional uncertainties in the M-factor calculation, e.g., due to random telegraph pixels (see Sect. 2 and discussion below), the M-factor approach is omitted for $\mathrm{XCH}_{4}$.

It has been identified that at times the WFMDv2.0 $\mathrm{XCH}_{4}$ results for specific orbits since 2005 suffer from outliers (too high or too low values beyond natural variability), most likely due to non-optimal dark signal correction caused by random telegraph detector pixels in channel 6+. These pixels jump spontaneously and unpredictably on varying timescales between two or more quasi-stable levels of the dark current leading to different detected signals for the same intensity. Thus, the dark current during the SCIAMACHY measurement on the day side may differ significantly from the reference dark current measured at the night side for affected pixels. In these cases a wrong dark signal is subtracted from the measurement. This results in retrieved total columns and 


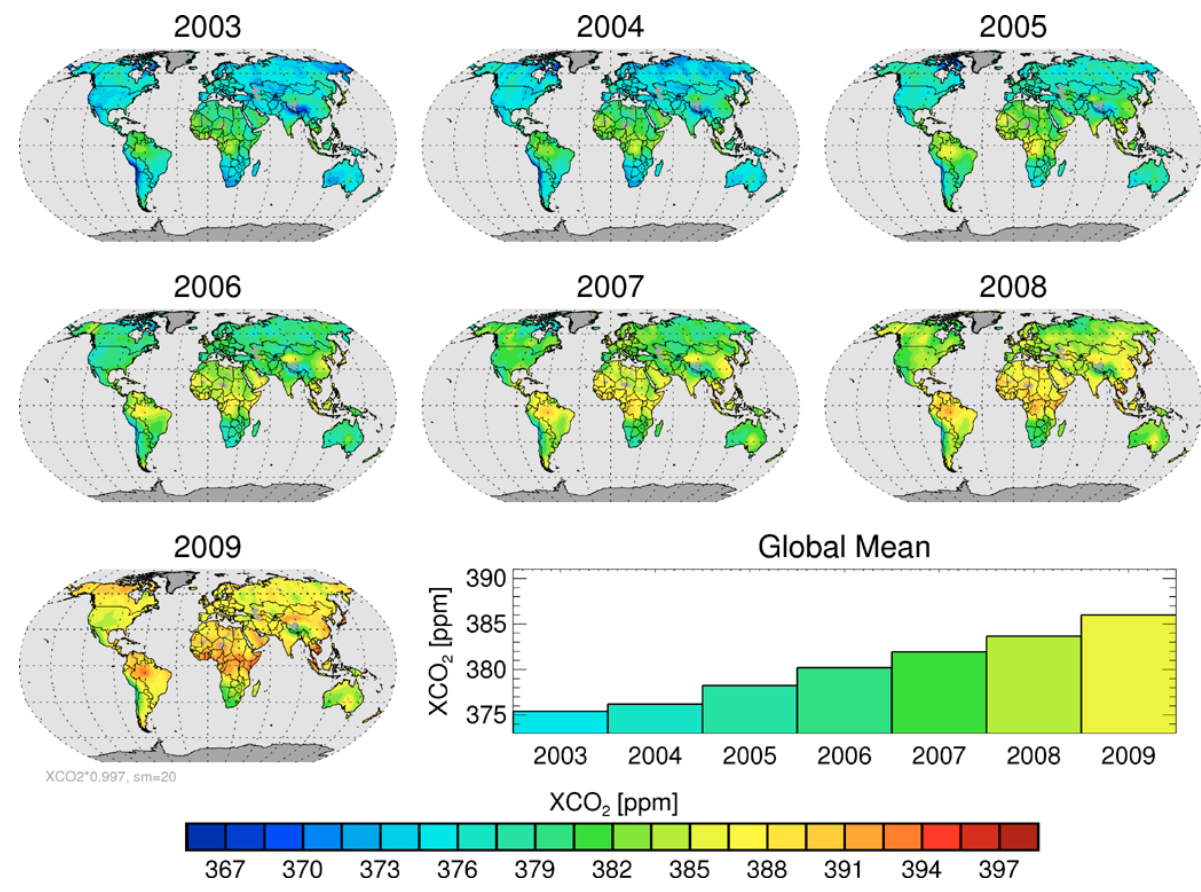

Fig. 2. Annual composite averages of quality filtered $\mathrm{WFMDv} 2.1 \mathrm{XCO}_{2}$ for the years 2003-2009. Also shown are the corresponding global means demonstrating the steady increase of the retrieved carbon dioxide with time. The standard error on the global means is about 0.01 ppm. This estimate is confirmed by a bootstrapping technique.

mole fractions that are too high or too low, although the fits are still good. Therefore, a filtering solely based on fit residuals cannot exclude affected measurements. To exclude corresponding orbits in the post-processing a threshold filter based on the absolute retrieved mole fractions has been implemented. If the mean of all retrieval results of one or more states in an orbit is less than $1600 \mathrm{ppb}$ or greater than $1900 \mathrm{ppb}$, all measurements of this orbit are flagged bad. As desired, this approach only filters orbits exhibiting systematically too high or too low values because the threshold test is performed on the entire state and not on the single measurement. This filter is complemented by excluding remaining outlier orbits by visual inspection. However, over $90 \%$ of all eventually filtered outlier orbits are already detected by the automated state-based threshold algorithm. The corresponding data product after filtering is denoted by WFMDv2.0.2 with which all methane results presented here are derived.

The single ground pixel retrieval precision derived from averaging daily standard deviations of the retrieved $\mathrm{XCH}_{4}$ (Schneising et al., 2009) for 8 locations distributed around the globe provides a consistent estimate of the single measurement precision of about $30 \mathrm{ppb}$ before November 2005 (70 ppb afterwards), respectively, which corresponds approximately to $1.7 \%(4 \%)$.

\section{Discussion of results}

All SCIAMACHY spectra (Level $1 \mathrm{~b}$ version 6 converted to Level $1 \mathrm{c}$ by the ESA SciaL1C tool using the standard calibration) for the years 2003-2009 which have been made available by ESA/DLR, have been processed using the improved retrieval algorithm WFM-DOAS version 2.0/2.1. The respective carbon dioxide and methane results are discussed separately in the following subsections.

\subsection{Carbon dioxide}

The resulting annual composite averages of atmospheric $\mathrm{XCO}_{2}$ after quality filtering for the years 2003-2009 are shown in Fig. 2 exhibiting similar patterns for all years superposed by a steady quite homogeneous increase with time. A significant part of the $\mathrm{CO}_{2}$ spatial variations shown in Fig. 2 results from the irregular sampling of the SCIA$\mathrm{MACHY} \mathrm{XCO}_{2}$. For example, the mid- and high-latitudes of the Northern Hemisphere are strongly weighted towards late spring, summer, and early autumn, where $\mathrm{CO}_{2}$ is known to be much lower than for the (true) yearly average. This uneven weighting is due to the significantly higher cloud cover in winter but also because of larger solar zenith angles and snow coverage. As a result, most of the mid- and high-latitude measurements in winter are automatically filtered out by the implemented quality filtering scheme. 


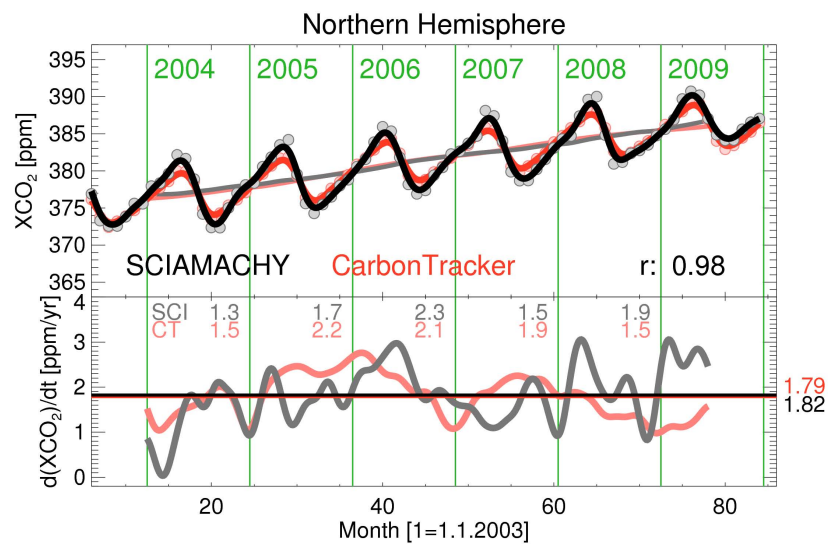

Table 1. Mean amplitude of seasonal cycle and annual increase for SCIAMACHY and CarbonTracker $\mathrm{XCO}_{2}$ for the two hemispheres and other latitude bands (see main text for details).

\begin{tabular}{ccccc}
\hline Latitude band & \multicolumn{2}{c}{$\begin{array}{c}\text { Mean amplitude } \\
\text { seasonal cycle } \\
{[\mathrm{ppm}]}\end{array}$} & \multicolumn{2}{c}{$\begin{array}{c}\text { Annual increase } \\
{\left[\mathrm{ppm} \mathrm{yr}^{-1} \text { ] }\right.}\end{array}$} \\
& SCIA & CT & SCIA & CT \\
\hline Global & $2.8 \pm 0.2$ & $1.7 \pm 0.1$ & $1.80 \pm 0.13$ & $1.81 \pm 0.09$ \\
$\mathrm{NH}$ & $4.3 \pm 0.2$ & $3.0 \pm 0.1$ & $1.82 \pm 0.16$ & $1.79 \pm 0.12$ \\
$\mathrm{SH}$ & $1.4 \pm 0.2$ & $0.9 \pm 0.1$ & $1.74 \pm 0.19$ & $1.83 \pm 0.07$ \\
$30^{\circ} \mathrm{N}-90^{\circ} \mathrm{N}$ & $4.9 \pm 0.1$ & $3.5 \pm 0.1$ & $1.90 \pm 0.20$ & $1.74 \pm 0.13$ \\
$30^{\circ} \mathrm{S}-30^{\circ} \mathrm{N}$ & $1.3 \pm 0.2$ & $0.7 \pm 0.1$ & $1.74 \pm 0.14$ & $1.84 \pm 0.08$ \\
$30^{\circ} \mathrm{S}-90^{\circ} \mathrm{S}$ & $1.5 \pm 0.3$ & $0.7 \pm 0.1$ & $1.88 \pm 0.27$ & $1.84 \pm 0.06$ \\
\hline
\end{tabular}

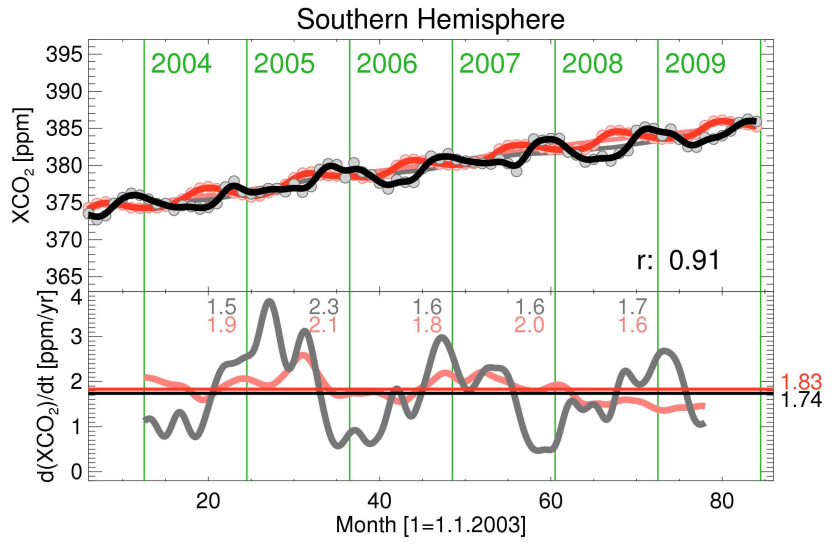

with CarbonTracker the SCIAMACHY $\mathrm{CO}_{2}$ data have been scaled by a constant factor of 0.997 to compensate for a small systematic bias between the two data sets. As can be seen in Fig. 3, the continuous increase with time on both hemispheres is consistent with CarbonTracker. The annual mean increase agrees with the model simulations within the error bars, namely about $1.8 \pm 0.2 \mathrm{ppm} \mathrm{yr}^{-1}$ compared to $1.8 \pm 0.1 \mathrm{ppm} \mathrm{yr}^{-1}$, respectively (see also Table 1 and the corresponding discussion below). Results of the first half of 2003 are not shown in this figure due to changes of the instrument settings, e.g., detector temperatures and field of view (shift of nadir centre position and change of total scan width), during the first third of 2003 . These changes potentially introduce small offsets in the data adversely affecting this particular quantitative analysis with impact until midyear because of the smoothing window used.

For the Northern Hemisphere we also find good agreement of the phase of the $\mathrm{CO}_{2}$ seasonal cycle with the model resulting in a pronounced correlation of the two data sets $(r=0.98)$. In contrast to the Northern Hemisphere, the seasonal cycle is less pronounced in the Southern Hemisphere and systematic phase differences are observed leading to a somewhat smaller correlation $(r=0.91)$ which is, nevertheless, quite high due to the observed consistent increase with time in both data sets. The discrepancy of the phases in the Southern Hemisphere can probably be ascribed to a large extent to the higher weight on ground scenes with occurrences of subvisual thin cirrus (induced by the restriction to land and the smaller land fraction compared to the Northern Hemisphere). Cirrus clouds are not explicitly considered in WFM-DOAS yet and are hence a potential error source leading to a possible overestimation of the carbon dioxide mole fractions for scenes with high subvisual cirrus fraction (Schneising et al., 2008). This could also be an explanation for the presumably unrealistically large cycle of the carbon dioxide growth rate in the Southern Hemisphere. The first promising results for synthetic data obtained with a different approach which is based on very time-consuming online radiative transfer calculations demonstrate that accurate retrievals are also possible in 
the presence of thin cirrus clouds (Reuter et al., 2010). This is achieved by including selected cloud parameters in the state vector. These findings indicate that cirrus can in principle also be considered explicitly in the future in a look-up table approach, even though it is not trivial to achieve sufficient processing speed for a global long-term analysis like the one presented in this manuscript. Although cloud parameters are not included in the state vector of the current WFM-DOAS version, the influence of subvisual cirrus on the retrievals is minimised resulting in much better agreement with CarbonTracker compared to the previous WFMDOAS version especially in the Southern Hemisphere. The achieved reduction of the amplitude of the seasonal cycle is presumably a consequence of the interaction of the more realistic default aerosol scenario, the application of M-factors in the calibration, improved spectroscopy, and the changeover to the SCIAMACHY Absorbing Aerosol Index. We find that for both hemispheres the mean amplitude of the retrieved seasonal cycle is on average about $1 \mathrm{ppm}$ larger than for CarbonTracker deriving $4.3 \pm 0.2 \mathrm{ppm}$ for the Northern Hemisphere and $1.4 \pm 0.2 \mathrm{ppm}$ for the Southern Hemisphere from the SCIAMACHY data (see Table 1). In contrast to the growth rates, the seasonal cycle amplitude differences between SCIAMACHY and CarbonTracker are significant. The less pronounced seasonal cycle of CarbonTracker compared to the satellite data might be explainable to some extent by a too low net ecosystem exchange (NEE) between the atmosphere and the terrestrial biosphere; for example Yang et al., 2007 estimate that NEE in the Northern Hemisphere is about 25\% larger than predicted by the CASA (CarnegieAmes Stanford Approach) biogeochemical model which is also used in CarbonTracker. This underestimation is of the same order of magnitude as the scaling needed to fit the amplitude of the northern hemispheric seasonal cycle of CarbonTracker to SCIAMACHY $(\approx 38 \%$, see Fig. 4$)$. On the other hand, it cannot be completely excluded that undetected seasonally varying thin cirrus clouds might also contribute to some extent to the observed differences in the seasonal cycle amplitudes because the seasonal cycle of the differences is somewhat similar in the Northern and Southern Hemisphere (see Fig. 5).

The exact values of mean annual increase and amplitudes of the seasonal cycle for both data sets and for both hemispheres as well as for several other latitude bands are summarised in Table 1. The stated increase is derived from the derivative of the deseasonalised trend as shown in Fig. 3 averaged over the whole time period and the associated uncertainties are estimated by a bootstrapping technique calculating twice the standard deviation of a set of growth rates obtained by random sampling of the original growth rate time series with replacement. Both data sets agree within their error bars regarding annual atmospheric carbon dioxide increase. According to NOAA/ESRL (http://www.esrl.noaa.gov/gmd/ ccgg/trends/) the average annual mean global carbon dioxide growth rate of marine surface sites which are assimilated in

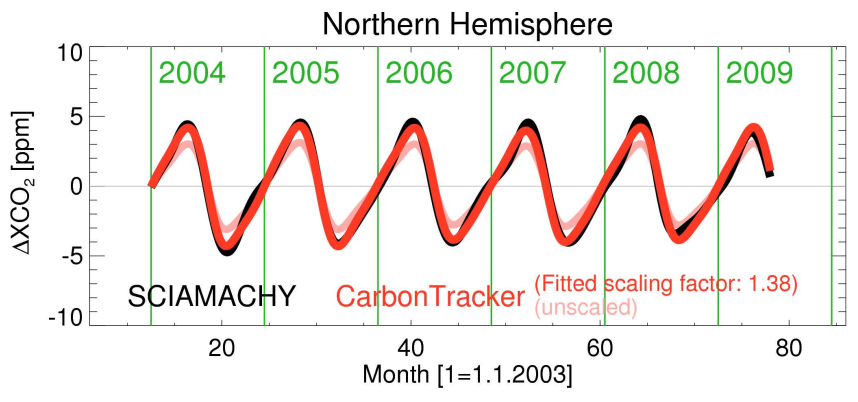

Fig. 4. Least-squares fit of CarbonTracker to SCIAMACHY $\mathrm{XCO}_{2}$ for the Northern Hemisphere after subtraction of the deseasonalised trend with a scaling factor as fit parameter showing that an upscaling of $38 \%$ is needed to fit the amplitude of the seasonal cycle of CarbonTracker to SCIAMACHY.
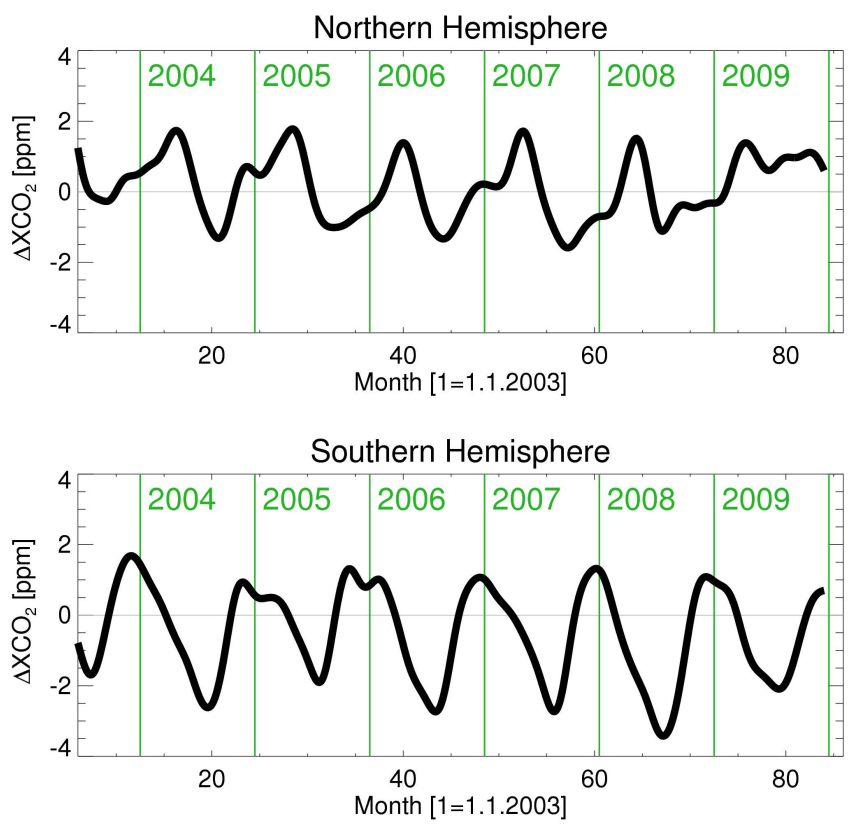

Fig. 5. Difference of the smoothed SCIAMACHY and CarbonTracker $\mathrm{XCO}_{2}$ of Fig. 3 for both hemispheres.

CarbonTracker for the relevant time period of Fig. 3 (20042009 ) is $1.89 \mathrm{ppm} \mathrm{yr}^{-1}$ with an estimated uncertainty in the annual mean growth rate of $0.07 \mathrm{ppm} \mathrm{yr}^{-1}$. However, due to the application of the SCIAMACHY averaging kernels, the age of air issue with growth rates of the past mixing in at high altitudes, uncertainties in the transport, and the consideration of the SCIAMACHY sampling in space and time, these surface results cannot be compared directly to the columnaveraged results presented here leading to larger uncertainties of CarbonTracker and to differing absolute values of the mean global growth rate compared to the surface data. Nevertheless, the value of the surface growth rate agrees within errors with the global SCIAMACHY and CarbonTracker results underlining the consistency of both data sets. 

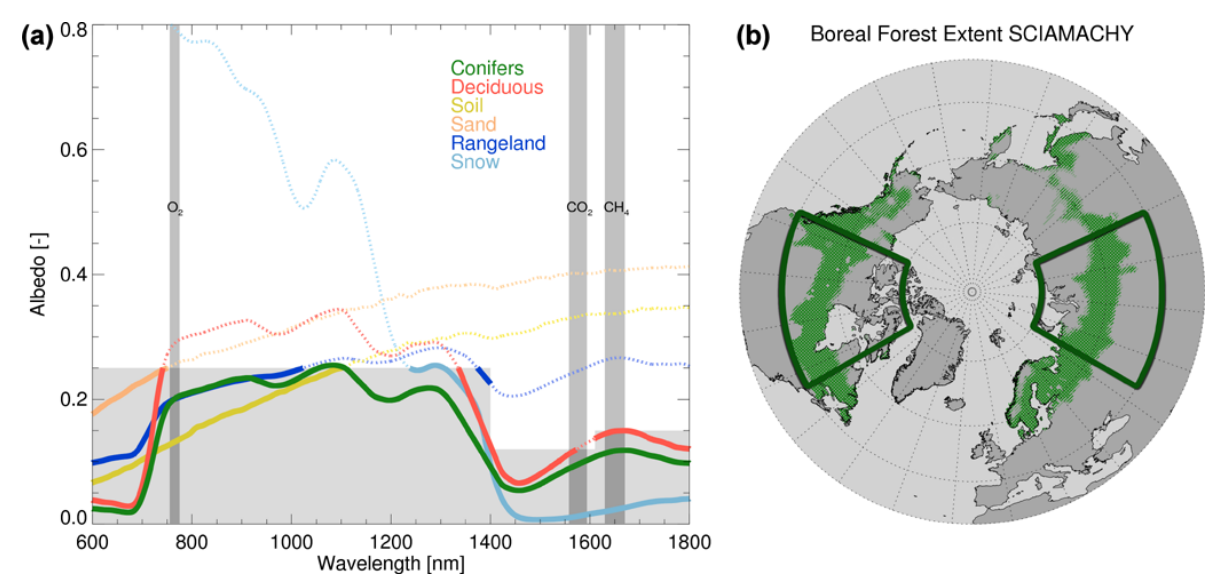

Fig. 6. Selection of the regions for the boreal forest carbon dioxide uptake analysis. The global conifer distribution can be extracted using specific thresholds on the retrieved albedos in the three WFM-DOAS fitting windows $\left(\mathrm{O}_{2}, \mathrm{CO}_{2}\right.$, and $\left.\mathrm{CH}_{4}\right)$. The fitting windows, used thresholds, and spectral albedos of typical natural land surface types (reproduced from the ASTER Spectral Library through the courtesy of the Jet Propulsion Laboratory, California Institute of Technology, Pasadena, California ( ${ }^{\circ} 1999$, California Institute of Technology) and the Digital Spectral Library 06 of the US Geological Survey) are shown in (a) demonstrating that only conifers pass the three window spectral albedo threshold filter. The deduced boreal forest extent is illustrated in (b). The highlighted region is used for the following analysis because it covers the bulk of the boreal forest area of the planet and the individual parts are equally sized and span the same latitude range ensuring similar solar zenith angles for the corresponding SCIAMACHY measurements.

The mean amplitude of the seasonal cycle is obtained by subtracting the deseasonalised trend from the smoothed curve and averaging the resulting amplitudes for all available years denoting the standard deviation as error. The amplitude of the seasonal cycle of the SCIAMACHY data is increasing in the Northern Hemisphere with higher latitudes in good qualitative agreement with CarbonTracker. Quantitatively, the differences of the amplitude values of the mid- and highlatitudes $\left(30^{\circ}-90^{\circ}\right)$ and the whole hemisphere are consistent for the SCIAMACHY and CarbonTracker data amounting to about $0.5 \mathrm{ppm}$ for the Northern Hemisphere. The absolute differences in the amplitudes of the retrieved and modelled seasonal cycle are on the order of $0.5-1.5 \mathrm{ppm}$ for all specified zonal averages.

\subsubsection{Boreal carbon uptake}

Another related aspect we analysed is the boreal forest carbon uptake during the growing season and its local partitioning between North America and Eurasia. To this end, we studied longitudinal gradients of atmospheric carbon dioxide during May-August (the period between the maximum and minimum of the seasonal cycle), which are the basic signals to infer regional fluxes, using the region motivated in Fig. 6 consisting of equally sized regions in North America and Russia covering the bulk of the boreal forest area of the planet. When an air parcel flows over the boreal forest, more and more carbon is steadily taken up by the growing vegetation leading to a gradient parallel to wind direction with smaller values at the endpoint compared to the starting point. Due to the fact that the prevailing wind direction in mid- to high-latitudes is from west to east, one would expect a negative west-to-east longitudinal gradient for the considered region because the air masses are mainly moving according to this wind direction over the uptake region. The absolute values of the derived gradients depend on the actual fine structure of the wind fields (temporary deviations from the prevailing wind direction).

The gradients are derived by calculating meridional averages of seasonally averaged (May-August) SCIAMACHY and CarbonTracker $\mathrm{XCO}_{2}$ as a function of longitude (in $0.5^{\circ}$ bins) and linear fitting the corresponding west-to-east gradient weighted according to the standard deviations of the meridional averages (see Fig. 7). The associated error is derived from the square root of the covariance of the linear fit parameter. The gradients for the whole considered time period 2003-2008 are listed in Table 2 showing that the results for SCIAMACHY and CarbonTracker agree within error bars in the overall region and the North American part and that the gradients in the Russian part differ by only $0.1 \mathrm{ppm}\left(100^{\circ}\right)^{-1}$ when taking the error bars into account. For the overall boreal forest region the respective longitudinal gradients which are linked to total flux strength are in good agreement amounting to $-2.5 \pm 1.7 \mathrm{ppm}\left(100^{\circ}\right)^{-1}$ for SCIAMACHY and $-2.3 \pm 0.6 \mathrm{ppm}\left(100^{\circ}\right)^{-1}$ for CarbonTracker. However, the SCIAMACHY data suggest that the main contribution to the gradient comes from the North American part of the region in contrast to CarbonTracker pointing to the Russian part. 

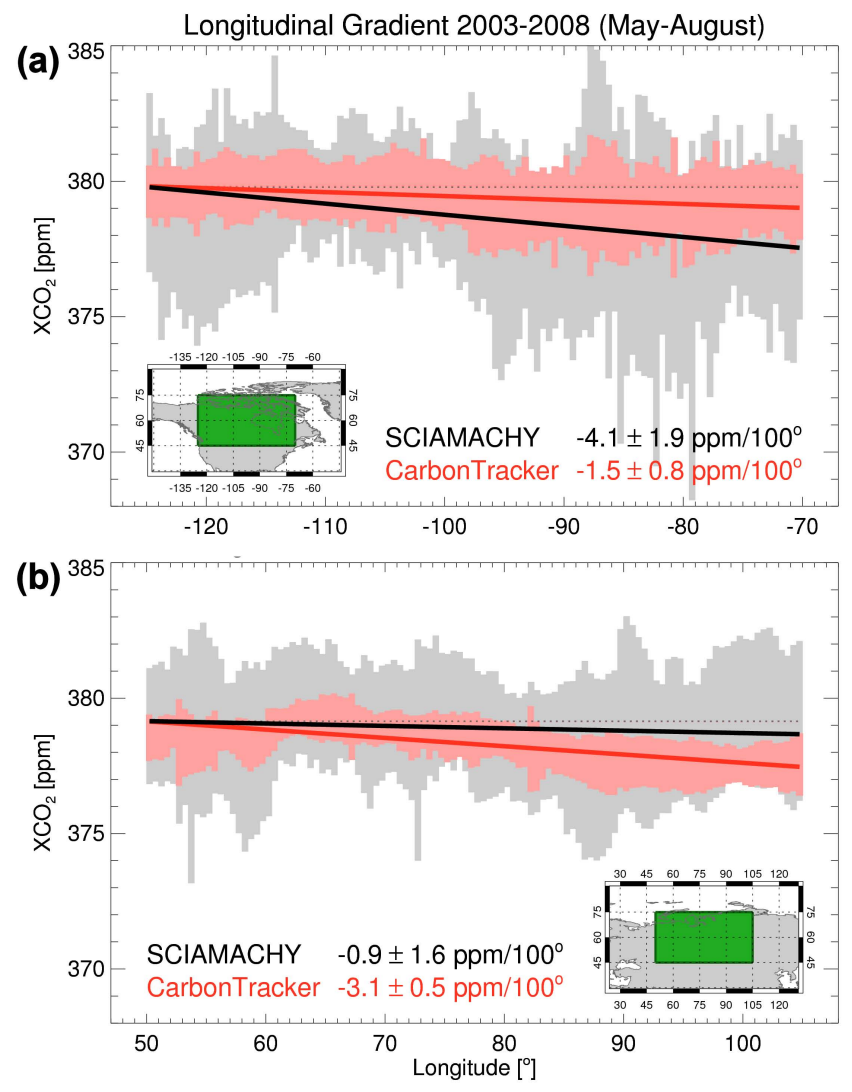

Fig. 7. Linear fits of the west-to-east longitudinal gradients of seasonally averaged (May-August) SCIAMACHY (black) and CarbonTracker (red) $\mathrm{XCO}_{2}$ during 2003-2008 for (a) North America and (b) Russia weighted according to the standard deviations (shaded areas) of the meridional averages $\left(0.5^{\circ}\right.$ bins $)$. The associated errors are derived from the square root of the covariance of the linear fit parameter.

The longitudinal gradients and their errors for the individual years are illustrated in Fig. 8. As expected, most of the gradients are negative. Taking the error bars into account the only significant positive longitudinal gradient occurs 2003 in Russia. Interestingly, this is true for SCIAMACHY and CarbonTracker indicating that there actually might have been something special in this region in this year. This could be potentially linked to the special meteorological situation during 2003 with one of the hottest summers on record in Europe. The gradients derived from SCIAMACHY and CarbonTracker show very similar inter-annual variations. The absolute values of the gradients are in good agreement for the combined North American and Russian boreal forest region (Fig. 8a). For North America (Fig. 8b) the gradients observed by SCIAMACHY are systematically larger (more negative) compared to CarbonTracker. However, both data sets agree within their error bars. For Russia (Fig. 8c) the single-year gradients also agree within their error bars but the observed gradients are systematically smaller (less neg-
Table 2. West-to-east longitudinal gradients of 2003-2008 $\mathrm{XCO}_{2}$ during the growing season (May-August) for the regions of Fig. 6. Also shown are the corresponding gradients for the shorter time period June-August minimising uncertainties due to potential regional timing errors in the onset of the forest uptake in the CASA model.

\begin{tabular}{|c|c|c|c|c|}
\hline \multirow[t]{2}{*}{ Boreal forest } & \multicolumn{2}{|c|}{$\begin{array}{c}\text { Longitudinal gradient } \\
\text { May-August } \\
{\left[\mathrm{ppm}\left(100^{\circ}\right)^{-1}\right]}\end{array}$} & \multicolumn{2}{|c|}{$\begin{array}{c}\text { Longitudinal gradient } \\
\text { June-August } \\
{\left[\operatorname{ppm}\left(100^{\circ}\right)^{-1}\right]}\end{array}$} \\
\hline & SCIA & CT & SCIA & CT \\
\hline Overall region & $-2.5 \pm 1.7$ & $-2.3 \pm 0.6$ & $-2.4 \pm 1.7$ & $-2.1 \pm 0.6$ \\
\hline North American part & $-4.1 \pm 1.9$ & $-1.5 \pm 0.8$ & $-3.5 \pm 1.8$ & $-1.6 \pm 0.6$ \\
\hline Russian part & $-0.9 \pm 1.6$ & $-3.1 \pm 0.5$ & $-1.3 \pm 1.5$ & $-2.6 \pm 0.5$ \\
\hline
\end{tabular}

ative) compared to CarbonTracker. Thus, the satellite data suggest a stronger North American boreal forest $\mathrm{CO}_{2}$ uptake than CarbonTracker and a weaker Russian boreal forest $\mathrm{CO}_{2}$ uptake. There is no obvious reason for assuming that this indication concerning the regional partitioning of the longitudinal gradients is affected by potential biases of the satellite data: errors caused by light path variations or residual spectroscopic errors (Schneising et al., 2008) are expected to have only a minor effect on the inferred gradients over these regions because the observations are taken at similar solar zenith angles and surface albedos and because the gradients do not depend on the absolute values of the retrieved $\mathrm{XCO}_{2}$ but only on regional differences.

The suggested difference between CarbonTracker and SCIAMACHY concerning the relative strengths of the Russian and North American boreal forest uptake might be linked to the recent finding of Keppel-Aleks et al., 2010 that modified CASA flux strengths and timings of the seasonal cycle introduce differences in corresponding gradients. Therefore, a potential regional timing error in the onset of the forest uptake in the CASA model might contribute to the difference between CarbonTracker and SCIAMACHY observed here. This potential contribution to the differences can be minimised by averaging over shorter time periods starting later. Actually, the restriction to June-August reduces the differences between CarbonTracker and SCIAMACHY concerning the relative regional uptake strengths to some extent and the gradients agree within error bars in all regions (see Table 2) indicating that regional timing uncertainties in the onset of the boreal forest uptake in the CASA model can contribute to the observed differences of the longitudinal gradients. This result is consistent with Keppel-Aleks et al., 2010. However, the qualitative findings concerning regional partitioning remain the same.

Figure 9 shows the spatial pattern during the growing season which leads to the derived longitudinal gradients of the North American boreal forest slice discussed above. Also depicted are the gradients based on the shown smoothed patterns derived by fitting linear combinations of a Gaussian and a quadratic polynomial to the SCIAMACHY and 

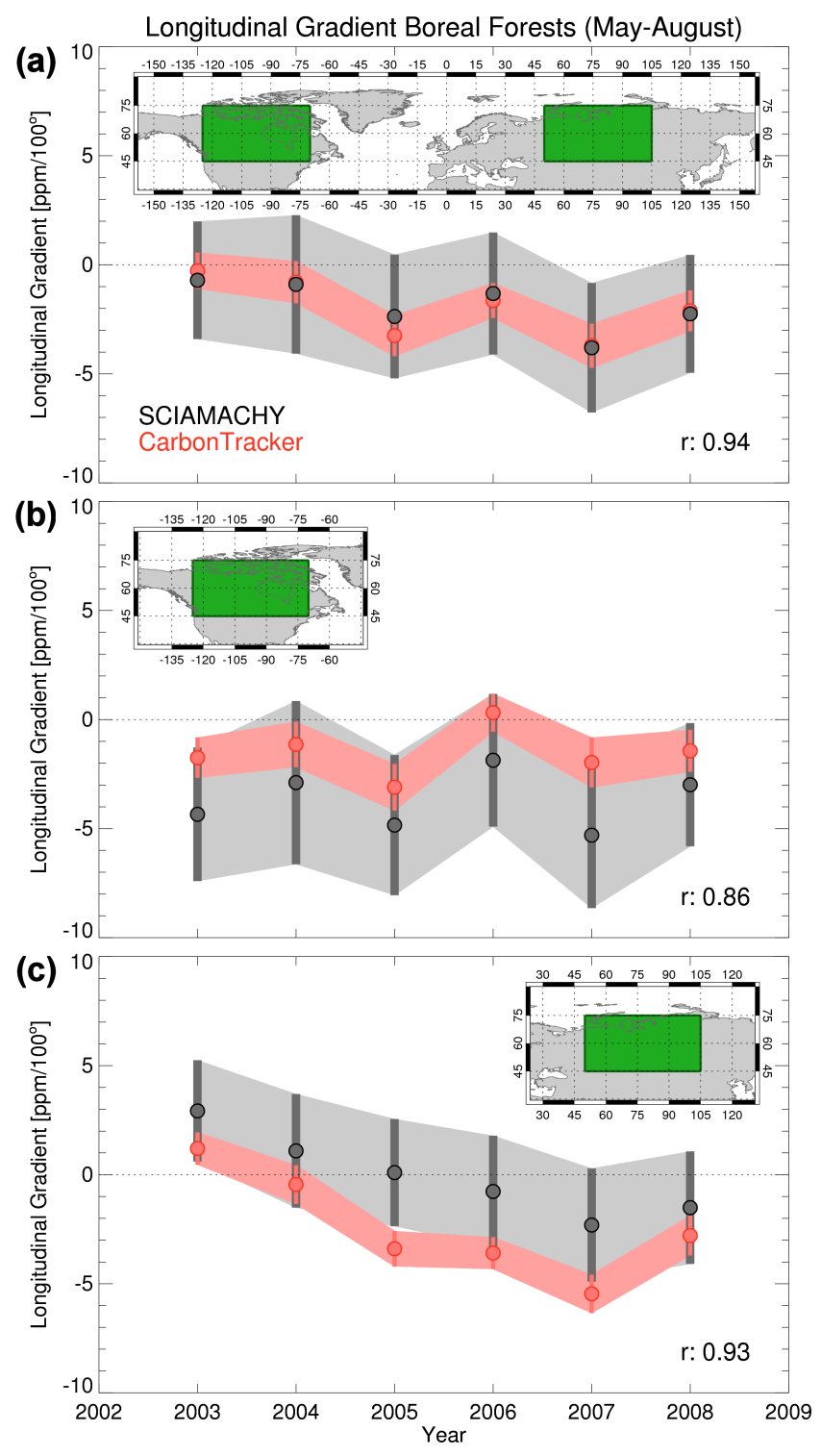

Fig. 8. Annual west-to-east longitudinal $\mathrm{XCO}_{2}$ gradients from SCIAMACHY (black) and CarbonTracker (red) for boreal forests during the growing season to infer the corresponding carbon dioxide uptake of the terrestrial biosphere. The examined boreal forest region is composed of the two equally sized regions in North America and Russia shown in green which was motivated in Fig. 6. The gradients and associated errors are illustrated for (a) the overall region (mean of the partial regions) and (b) the North American and (c) Russian part individually.

CarbonTracker data. However, Fig. 10 shows using the example of North America that there is also a complex curved north-south gradient during the growing season due to transport in the atmosphere which makes a direct translation of the differences in the observed partitioning of the longitudinal gradients to total flux strength difficult. In this context it has to be noted that linear fits might be insufficient to capture

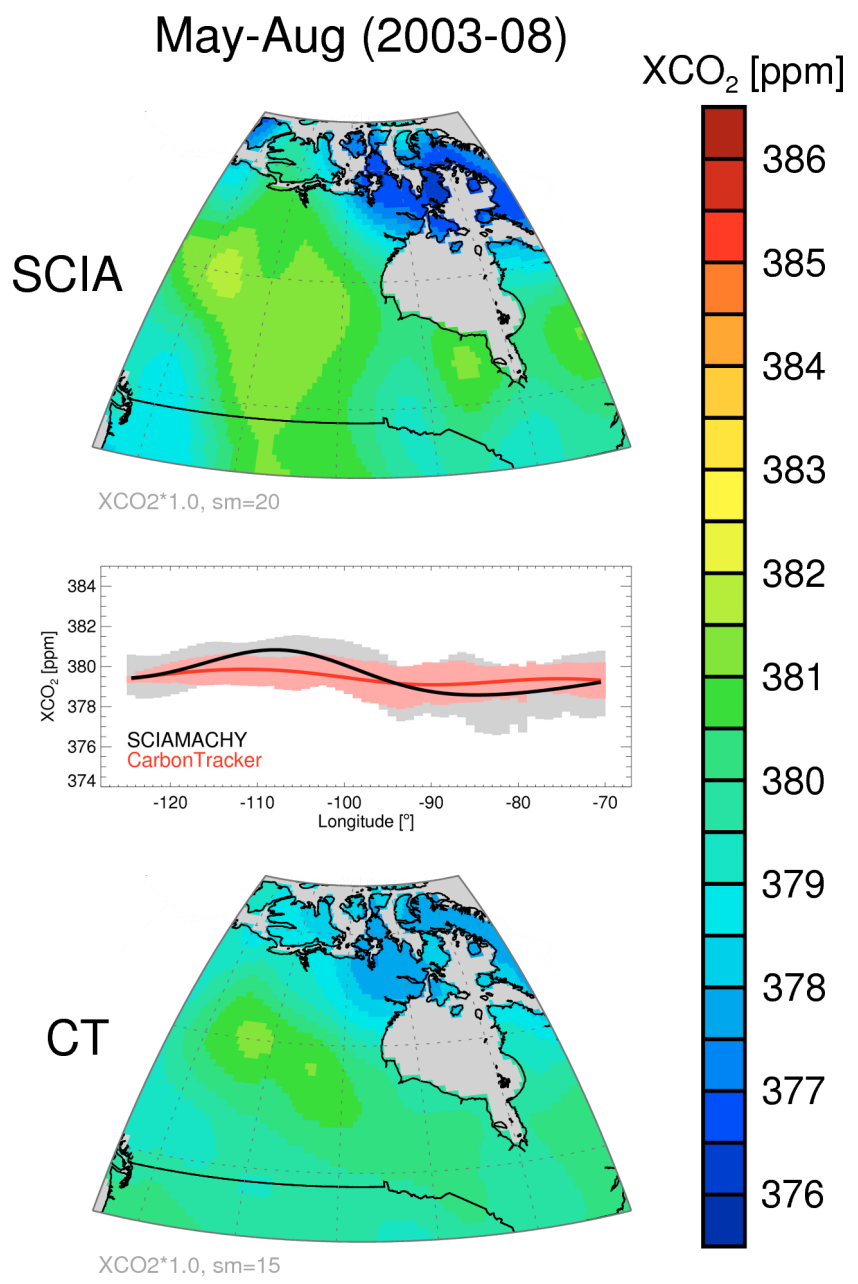

Fig. 9. Seasonally averaged (May-August) SCIAMACHY (top) and CarbonTracker (bottom) $\mathrm{XCO}_{2}$ during 2003-2008 over the North American boreal forest slice motivated in Fig. 6 showing the spatial pattern during the growing season which leads to the longitudinal gradients of Fig. 7a. The middle panel shows the gradients based on the smoothed pattern shown here derived by fitting linear combinations of a Gaussian and a quadratic polynomial.

the more complex structure of the gradients in the latitudinal case. Therefore, Fig. 10 shows fits of linear combinations of a Gaussian and a quadratic polynomial to the two data sets analogue to Fig. 9. The longitudinal/latitudinal fits of Figs. 9 and 10 for SCIAMACHY and CarbonTracker are highly correlated ( $r=0.90$ in the longitudinal and $r=0.99$ in the latitudinal case), although SCIAMACHY seems to be more sensitive to changes in the meridional/zonal averages.

\subsection{Methane}

Figure 11 shows quality filtered annual composite averages of atmospheric $\mathrm{XCH}_{4}$ for the years 2003-2009. Clearly visible are major methane source regions and the interhemispheric gradient. Due to proceeding detector degradation in 
SCIA May-Aug (2003-08)

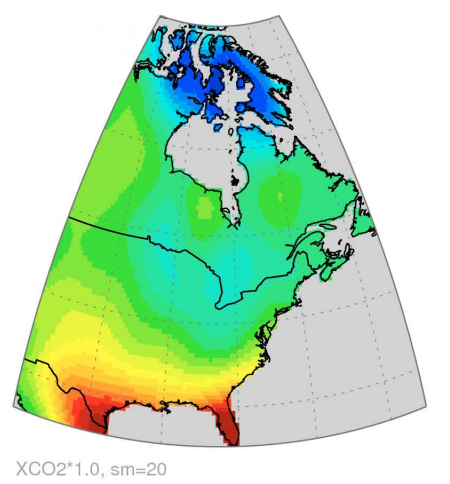

CT May-Aug (2003-08)

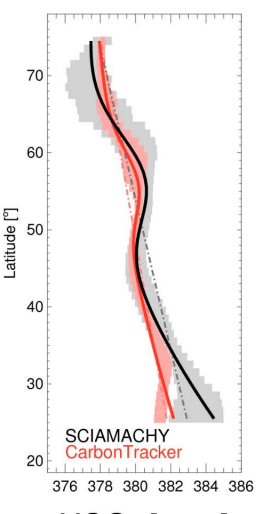

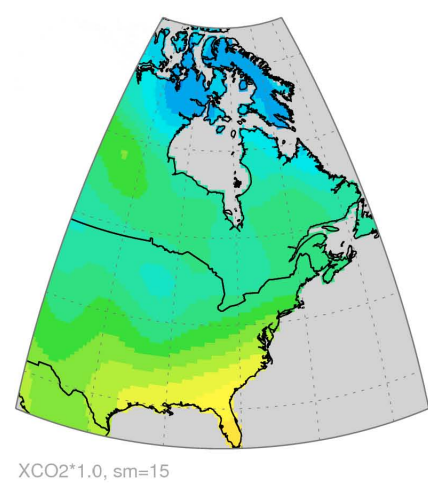

$\mathrm{XCO} 2^{*} 1.0, \mathrm{sm}=15$

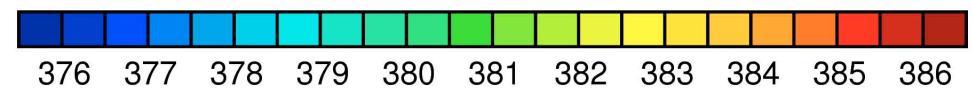

Fig. 10. Seasonally averaged (May-August) SCIAMACHY (left) and CarbonTracker (right) $\mathrm{XCO}_{2}$ during 2003-2008 over North America demonstrating that there is also a complex curved north-south gradient in the atmosphere during the growing season. The corresponding latitudinal gradients derived by fitting linear combinations of a Gaussian and a quadratic polynomial are shown in the middle panel as solid black and red lines together with the standard deviations (shaded regions) of the zonal $\mathrm{XCO}_{2}$ averages $\left(0.5^{\circ}\right.$ bins). The dash-dotted pale straight lines are linear fits of the gradients.
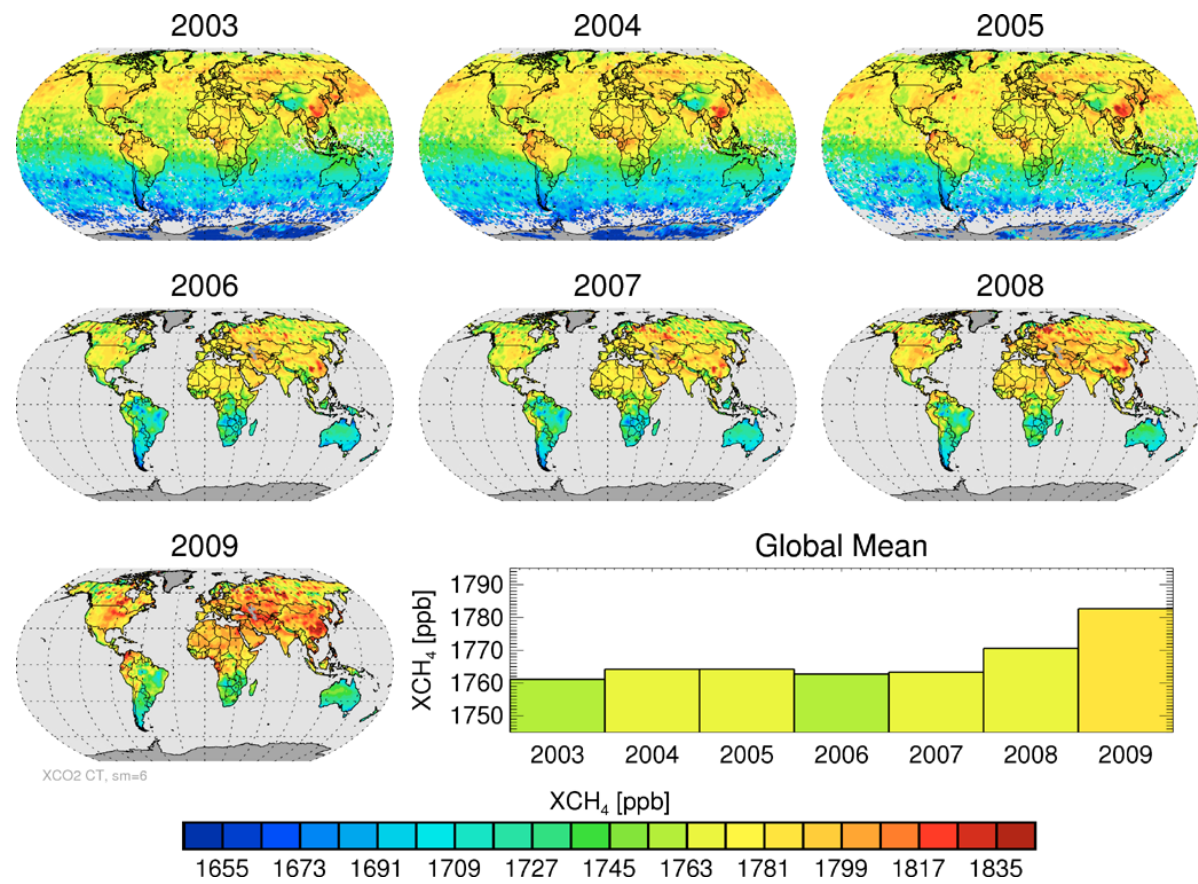

Fig. 11. As Fig. 2 but for WFMDv2.0.2 $\mathrm{XCH}_{4}$. Due to proceeding detector degradation in the spectral range used for the methane column retrieval and the corresponding availability of considerably fewer detector pixels the results since November 2005 exhibit larger scatter (see also Fig. 12). For this reason and because of the larger noise over oceans the results after October 2005 are restricted to land only. As can be seen, after years of near-zero growth, the globally averaged atmospheric methane started to increase again in recent years. The standard error on the global means is about $0.04 \mathrm{ppb}$ before 2006 and $0.07 \mathrm{ppb}$ since 2006 . These estimates are confirmed by a bootstrapping technique. 


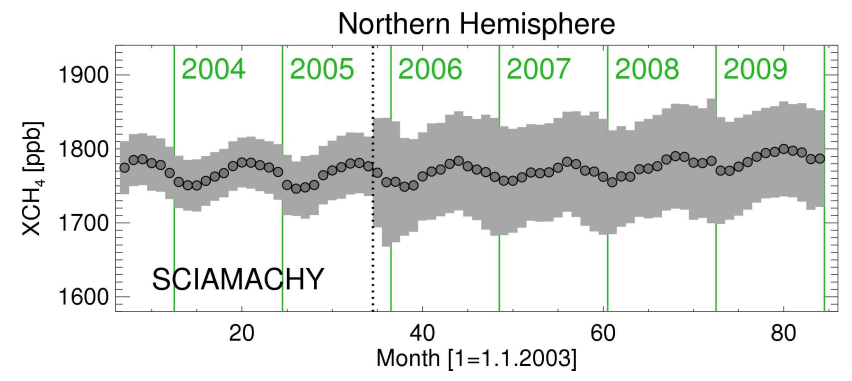

Fig. 12. Monthly means of northern hemispheric SCIAMACHY WFMDv2.0.2 $\mathrm{XCH}_{4}$ and corresponding standard deviations demonstrating that the scatter since the pixel mask alteration at the end of October 2005 is on average about twice as large. Nevertheless, the seasonal cycle of the monthly means can still be clearly observed.

the spectral range used for the methane column retrieval and the corresponding availability of considerably fewer detector pixels the results since November 2005 are of reduced quality manifesting itself in particular by larger scatter. Figure 12 demonstrates using the example of the Northern Hemisphere that the standard deviation of the monthly means since the pixel mask change at the end of October 2005 is on average about twice as large. Nevertheless, the seasonal cycle of the monthly means can still be clearly observed. The pixel mask alteration at the end of October 2005 might potentially also introduce systematic regional biases; e.g., it seems that the tropical enhancement relative to the surrounding areas is less pronounced 2006-2009 compared to 2003-2005 indicating that the magnitude of the retrieved tropical methane enhancement not only depends on the used spectroscopic parameters in the forward model (Frankenberg et al., 2008b; Schneising et al., 2009; Bergamaschi et al., 2009) but also on the detector pixel mask used. This is supported by the fact that a reanalysis of a subset of pre-2005 data (November 2004) with the pixel mask from November 2005 provides latitudinal averages similar to later years with less methane in the tropics (see Fig. 13). The analysis of the global mean values shows that after years of near-zero growth, atmospheric methane started to increase again in recent years which is qualitatively consistent with the findings of Rigby et al., 2008 and Dlugokencky et al., 2009 for surface methane concentrations. In this context it has to be pointed out that a static pixel mask is used for 2006-2009 containing only detector pixels that are not turning dead or bad during this period (according to the flagging provided by SRON which is available for Orbits until March 2009) to ensure that the observed growth is not artificially introduced by proceeding detector degradation. This is also supported by the fact that the fit quality is stable for the whole considered time period 2003-2009 indicating that there are actually no dead or bad detector pixels which are not excluded in the used pixel mask approach.

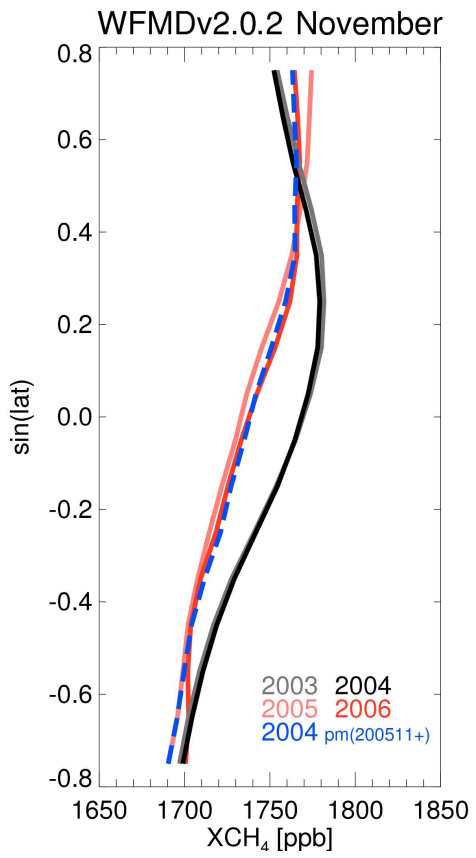

Fig. 13. Reanalysis of a subset of pre-2005 data (November 2004) with the pixel mask since November 2005 (shown in dashed blue) providing monthly latitudinal averages similar to later years with less methane retrieved in the tropics. This suggests that the pixel mask alteration potentially introduces systematic regional biases.

To examine this renewed methane increase in recent years more quantitatively Fig. 14 shows the temporal evolution of retrieved SCIAMACHY methane based on monthly means as well as the corresponding deseasonalised trend and its derivative for both hemispheres analogue to Fig. 3 for carbon dioxide. The already mentioned larger scatter since November 2005 due to the decreased number of usable detector pixels is also observed in the monthly data. This is in particular true for the Southern Hemisphere where the stricter filter criteria accompanying the pixel mask change lead to considerably fewer measurements available for the computation of the monthly means because of the additional exclusion of scenes over oceans and the relatively small land mass fraction. Nevertheless, the renewed methane growth is visible in Fig. 14 for both hemispheres.

The anomaly since 2007 is derived from the difference of the mean values of the derivative of the deseasonalised trend after and before middle of 2006. To avoid a possible distortion of the analysed curves due to potentially introduced systematic regional biases caused by the alteration of the detector pixel mask at the end of October 2005, all values over a period of plus or minus 6 months from this date are not considered in the calculation of the mean value before 2007 .

It would be desirable to have model simulations for the whole time period 2003-2009 for a quantitative comparison of the respective anomalies. In this study we use Scenario S1 of Bergamaschi et al., 2007 (based on the NOAA surface 

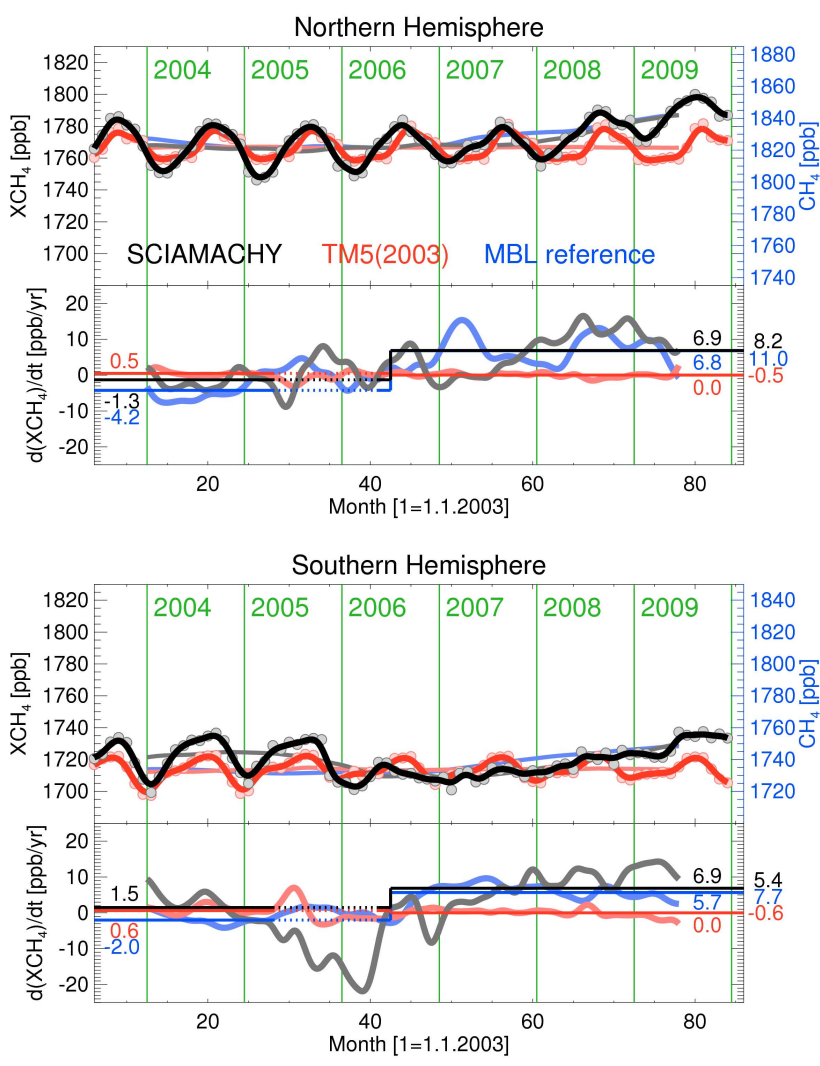

Fig. 14. As Fig. 3 but for WFMDv2.0.2 $\mathrm{XCH}_{4}$. The anomaly (numbers on the right border) is defined as the difference of the mean values of the derivative of the deseasonalised trend after and before middle of 2006. Values one year around the detector pixel mask alteration end of October 2005 (indicated by the dotted lines) are not considered because systematic offsets due to the change are potentially distorting the deseasonalised trend (obtained by smoothing) and its derivative. As the TM5 model is only available for 2003, the corresponding values are repeated every year to study the amplitudes of the seasonal cycles and the impact of sampling on the observed anomaly because it is expected to be zero for the repeated model if there is no sampling influence. Hence, the anomaly of the model is a lower bound of the error of the observed SCIAMACHY anomaly. To assess the expected absolute values and temporal evolution of the increase at least approximately, the SCIAMACHY data are also compared to the deseasonalised trend of the Marine Boundary Layer reference matrix derived using NOAA/ESRL surface measurements averaged over the respective hemisphere (blue). The MBL reference data through 2009 are preliminary.

measurements) of the TM5 model (Krol et al., 2005). Unfortunately, the TM5 model data set is currently only available for 2003. The corresponding values are repeated every year to study at least the seasonal behaviour. For this analysis the SCIAMACHY data are scaled with 0.995 to be on the same level as the model data in 2003. The TM5 fields as used for this study have been sampled in space and time as the SCIAMACHY satellite instrument measures. The SCIAMACHY altitude sensitivity has been taken into account by applying the SCIAMACHY $\mathrm{CH}_{4}$ column averaging kernels to the model vertical profiles. Of course, the expected anomaly since 2007 for this yearly repeated model is zero. Nevertheless, a deviation from zero is a measure of the impact of sampling in particular due to the different filter criteria after October 2005; e.g., the restriction to land leads to a smaller seasonal cycle for the Southern Hemisphere being visible in both the satellite and model data. Hence, the anomaly of the model is a lower bound of the error of the observed SCIAMACHY anomaly. Neglecting other possible error sources the anomaly of SCIAMACHY $\mathrm{XCH}_{4}$ amounts to $8.2 \pm 0.5 \mathrm{ppb} \mathrm{yr}^{-1}$ for the Northern Hemisphere and $5.4 \pm 0.6 \mathrm{ppb} \mathrm{yr}^{-1}$ for the Southern Hemisphere. The contribution of the restriction to land after October 2005 to the sampling error of the anomalies is smaller than $0.2 \mathrm{ppb} \mathrm{yr}^{-1}$ as estimated by additionally restricting to land for the whole time series and comparing the respective anomalies to the previously derived values. Hence, the potential error of the anomalies induced by using land and ocean scenes before and land only scenes after the end of October 2005 is small. This is a reasonable result because the amount of available data over the ocean is comparatively thin, anyway.

To assess the expected absolute values and temporal evolution of the increase at least approximately, the SCIAMACHY data are also compared to the Marine Boundary Layer reference matrix derived using NOAA/ESRL surface measurements from sites which are believed to be representative of large well-mixed marine air masses (Dlugokencky et al., 2010) and the data extension and integration techniques described by Masarie and Tans, 1995. The MBL reference data through 2009 are preliminary. As the phase of the seasonal cycle of methane can differ for column-averaged and surface data, only the deseasonalised trends for the hemispheric averages of the MBL reference matrix are shown in Fig. 14. The deseasonalised trends of the satellite and surface data are in reasonable to good agreement in particular for the Northern Hemisphere when considering the different absolute values of the data sets because surface data are always higher than column-averaged data (note the different $y$ axes). The derived surface anomaly values of $11.0 \mathrm{ppb} \mathrm{yr}^{-1}$ for the Northern Hemisphere and $7.7 \mathrm{ppb} \mathrm{yr}^{-1}$ for the Southern Hemisphere are only a coarse estimate of the magnitude of the expected hemispheric column-averaged anomalies as seen by SCIAMACHY due to the limitations of comparability between surface and satellite trends already explained in the discussion of the carbon dioxide results. In conformity with expectations the actual corresponding SCIAMACHY values stated above are smaller than for the surface measurements. Additionally, the northern hemispheric anomalies for both data sets are higher than for the Southern Hemisphere (about $3 \mathrm{ppb} \mathrm{yr}^{-1}$ in both cases) further indicating that the values derived from the satellite data are consistent with the surface measurements and seem reasonable. 
Table 3. Mean amplitude of seasonal cycle and observed annual anomaly since 2007 for SCIAMACHY and TM5 $\mathrm{XCH}_{4}$ for the two hemispheres and other latitude bands. The anomaly of the model (2003 repeated) is an estimate of the impact of sampling because it is expected to be zero and is therefore a lower bound of the error of the SCIAMACHY anomaly.

\begin{tabular}{crrrr}
\hline Latitude band & \multicolumn{2}{c}{$\begin{array}{c}\text { Mean amplitude } \\
\text { seasonal cycle } \\
\text { [ppb] }\end{array}$} & \multicolumn{2}{c}{$\begin{array}{c}\text { Anomaly } \\
\text { since 2007 } \\
\text { [ppb yr }\end{array}$} \\
& SCIA & TM5(2003) & SCIA & TM5(2003) \\
\hline Global & $13.4 \pm 4.0$ & $9.8 \pm 2.9$ & 7.4 & -0.4 \\
$\mathrm{NH}$ & $13.7 \pm 2.6$ & $9.3 \pm 0.3$ & 8.2 & -0.5 \\
$\mathrm{SH}$ & $8.5 \pm 5.3$ & $8.5 \pm 1.7$ & 5.4 & -0.6 \\
$30^{\circ} \mathrm{N}-90^{\circ} \mathrm{N}$ & $12.4 \pm 8.0$ & $11.2 \pm 0.8$ & 6.6 & -0.6 \\
$30^{\circ} \mathrm{S}-30^{\circ} \mathrm{N}$ & $7.3 \pm 3.7$ & $5.1 \pm 0.9$ & 8.2 & -0.2 \\
$30^{\circ} \mathrm{S}-90^{\circ} \mathrm{S}$ & $10.6 \pm 1.2$ & $8.5 \pm 3.1$ & 4.4 & 0.0 \\
$0^{\circ} \mathrm{N}-30^{\circ} \mathrm{N}$ & $17.2 \pm 1.9$ & $10.8 \pm 1.0$ & 9.1 & -0.4 \\
$0^{\circ} \mathrm{S}-30^{\circ} \mathrm{S}$ & $6.1 \pm 2.7$ & $5.2 \pm 0.3$ & 5.8 & -0.5 \\
\hline
\end{tabular}

According to Table 3, where also the results for other zonal averages are listed, the largest increase of the SCIAMACHY data is observed for the tropics and northern mid- and highlatitudes $\left(\approx 7.5 \pm 1.5 \mathrm{ppb} \mathrm{yr}^{-1}\right.$ since 2007$)$. This is consistent with Dlugokencky et al., 2009. The analysis of the seasonal variations shows that the mean amplitudes of the seasonal cycles of the SCIAMACHY data and the TM5 model typically differ by less than $4 \mathrm{ppb}$ for the analysed latitude bands.

\section{Conclusions}

This manuscript presented and discussed a long-term (20032009) global data set of atmospheric carbon dioxide and methane column-averaged dry air mole fractions retrieved from the spectral near-infrared/shortwave-infrared nadir observations of the SCIAMACHY instrument onboard the European environmental satellite ENVISAT using the improved version 2.0/2.1 of the scientific retrieval algorithm WFMDOAS.

To assess the quality of the data, we have performed comparisons with NOAA's global assimilation system CarbonTracker for carbon dioxide as well as with the TM5 model and surface measurements for methane focusing on seasonal variations and long-term increase. The amplitudes of the seasonal cycles of the satellite retrievals for the considered zonal averages are typically higher than for the model data: about $0.5-1.5 \mathrm{ppm}$ for $\mathrm{CO}_{2}$ and typically less than $4 \mathrm{ppb}$ for $\mathrm{CH}_{4}$. The corresponding phases are generally in reasonable to good agreement with the exception of southern hemispheric $\mathrm{XCO}_{2}$. This systematic difference is ascribed to seasonally varying subvisual thin cirrus cloud cover.

The continuous $\mathrm{CO}_{2}$ increase with time is obvious in both the SCIAMACHY data and the CarbonTracker reanal- ysis product. The retrieved global annual mean increase agrees with CarbonTracker within the error bars amounting to $1.80 \pm 0.13 \mathrm{ppm} \mathrm{yr}^{-1}$ compared to $1.81 \pm 0.09 \mathrm{ppm} \mathrm{yr}^{-1}$. To further examine the differences in the values of seasonal amplitude and to quantify the relative accuracy of the data, comparisons with independent column-averaged mole fraction data from ground-based Fourier Transform Spectrometers (FTS) are intended for the future. However, such a quantitative comparison will not be trivial due to the different averaging kernels of WFM-DOAS and FTS influencing the respective absolute amounts of retrieved seasonal variability and annual increase. Therefore, the differing sensitivities of the instruments have to be taken into account appropriately.

The investigation of the longitudinal gradients for boreal forests during the growing season being valuable to infer regional fluxes shows good agreement between SCIAMACHY and CarbonTracker concerning inter-annual variability and absolute values of the gradients for the overall region covering the bulk of the boreal forest area of the planet. The satellite results point to a stronger North American boreal forest uptake and a weaker Russian boreal forest uptake compared to CarbonTracker, although the yearly gradients determined from the two data sets agree within their error bars. In consistency with Keppel-Aleks et al., 2010 our analysis indicates that regional timing uncertainties in the onset of the boreal forest uptake in the CASA model which is used in CarbonTracker can contribute to the observed differences of the longitudinal gradients. However, due to the additional coexistence of complex curved varying north-south gradients in the atmosphere no strong conclusions about the regional partitioning of total flux strength can be drawn in the end.

The SCIAMACHY methane data are consistent with surface measurements reporting a renewed increase of atmospheric $\mathrm{CH}_{4}$ after years of near-zero growth. The largest retrieved increase from the SCIAMACHY data is observed for the tropics and northern mid- and high-latitudes amounting to about $7.5 \pm 1.5 \mathrm{ppb} \mathrm{yr}^{-1}$ since 2007 . However, a comparison of the anomaly with long-term column-averaged model data would be more suited to quantify the expected increase of the satellite data than the comparison based on surface data presented here. Therefore, it is planned for the future to compare the increase more quantitatively with the TM5 model being optimised versus the highly accurate surface measurements from the NOAA/ESRL network once the model runs are available for the whole time period 2003-2009 to assess the quality of the absolute values of the retrieved anomaly in more detail.

Future research will also analyse to what extent the larger noise on the methane data since November 2005 caused by detector degradation adversely affects the retrieval results when focusing on more regional applications which unavoidably leads to fewer measurements being available for averaging. In this context it would also be interesting to investigate if it is possible in certain circumstances by means of alternative calibration approaches to use detector pixels at 
wavelengths with strong methane absorption in the Q-branch of the $2 v_{3}$ band which are not useable when using the standard calibration.

Acknowledgements. We thank ESA and DLR for providing us with the SCIAMACHY Level 1 data and the SCIAMACHY calibration team (DLR, SRON, University of Bremen, ESA, and others) for continuously improving the quality of the spectra. CarbonTracker 2010 results were provided by NOAA ESRL, Boulder, Colorado, USA from the website at http://carbontracker.noaa.gov. We also thank NOAA ESRL for the the methane Marine Boundary Layer reference matrix and Peter Bergamaschi from EC-JRC for providing the TM5 methane model runs. SCIAMACHY Absorbing Aerosol Index data were obtained from the TEMIS website (http://www.temis.nl/airpollution/absaai/). We acknowledge SRON for providing the dynamic bad and dead pixel mask products. This paper has been significantly improved due to comments on earlier versions of the manuscript from Pieter Tans, NOAA.

The research leading to these results has received funding from the ESA project CARBONGASES which is part of The Changing Earth Science Network, the ESA projects GHG-CCI, ADVANSE, and ALANIS Methane, the European Union's Seventh Framework Programme (FP7/2007-2013) under Grant Agreement no. 218793 and 212095 (MACC and CityZen), the DLR grant SADOS, and from the University and the State of Bremen.

Edited by: R. Cohen

\section{References}

Aumann, H. H., Gregorich, D., and Gaiser, S.: AIRS hyperspectral measurements for climate research: carbon dioxide and nitrous oxide effects, Geophys. Res. Lett., 32, L05806, doi:10.1029/2004GL021784, 2005.

Barkley, M. P., Frieß, U., and Monks, P. S.: Measuring atmospheric $\mathrm{CO}_{2}$ from space using Full Spectral Initiation (FSI) WFMDOAS, Atmos. Chem. Phys., 6, 3517-3534, doi:10.5194/acp-63517-2006, 2006a.

Barkley, M. P., Monks, P. S., and Engelen, R. J.: Comparison of SCIAMACHY and AIRS $\mathrm{CO}_{2}$ measurements over North America during the summer and autumn of 2003, Geophys. Res. Lett., 33, L20805, doi:10.1029/2006GL026807, 2006b.

Barkley, M. P., Monks, P. S., Frieß, U., Mittermeier, R. L., Fast, H., Körner, S., and Heimann, M.: Comparisons between SCIAMACHY atmospheric $\mathrm{CO}_{2}$ retrieved using (FSI) WFM-DOAS to ground based FTIR data and the TM3 chemistry transport model, Atmos. Chem. Phys., 6, 4483-4498, doi:10.5194/acp-64483-2006, 2006c.

Barkley, M. P., Monks, P. S., Hewitt, A. J., Machida, T., Desai, A., Vinnichenko, N., Nakazawa, T., Yu Arshinov, M., Fedoseev, N., and Watai, T.: Assessing the near surface sensitivity of SCIAMACHY atmospheric $\mathrm{CO}_{2}$ retrieved using (FSI) WFM-DOAS, Atmos. Chem. Phys., 7, 3597-3619, doi:10.5194/acp-7-35972007, 2007.

Bergamaschi, P., Frankenberg, C., Meirink, J. F., Krol, M., Dentener, F., Wagner, T., Platt, U., Kaplan, J. O., Körner, S., Heimann, M., Dlugokencky, E. J., and Goede, A.: Satellite chartography of atmospheric methane from SCIAMACHY onboard
ENVISAT: 2. Evaluation based on inverse model simulations, J. Geophys. Res., 112, D02304, doi:10.1029/2006JD007268, 2007.

Bergamaschi, P., Frankenberg, C., Meirink, J. F., Krol, M., Villani, M. G., Houweling, S., Dentener, F., Dlugokencky, E. J., Miller, J. B., Gatti, L. V., Engel, A., and Levin, I.: Inverse modeling of global and regional $\mathrm{CH}_{4}$ emissions using SCIAMACHY satellite retrievals, J. Geophys. Res., 114, D22301, doi:10.1029/2009JD012287, 2009.

Bloom, A. A., Palmer, P. I., Fraser, A., Reay, D. S., and Frankenberg, C.: Large-scale controls of methanogenesis inferred from methane and gravity spaceborne data, Science, 327, 322-325, doi:10.1126/science.1175176, 2010.

Bösch, H., Toon, G. C., Sen, B., Washenfelder, R. A., Wennberg, P. O., Buchwitz, M., de Beek, R., Burrows, J. P., Crisp, D., Christi, M., Connor, B. J., Natraj, V., and Yung, Y. L.: Space-based near-infrared $\mathrm{CO}_{2}$ measurements: testing the Orbiting Carbon Observatory retrieval algorithm and validation concept using SCIAMACHY observations over Park Falls, Wisconsin, J. Geophys. Res., 111, D23302, doi:10.1029/2006JD007080, 2006.

Bousquet, P., Ciais, P., Miller, J. B., Dlugokencky, E. J., Hauglustaine, D. A., Prigent, C., Van der Werf, G. R., Peylin, P., Brunke, E.-G., Carouge, C., Langenfelds, R. L., Lathiere, J., Papa, F., Ramonet, M., Schmidt, M., Steele, L. P., Tyler, S. C., and White, J.: Contribution of anthropogenic and natural sources to atmospheric methane variability, Nature, 443, 439-443, doi:10.1038/nature05132, 2006.

Bovensmann, H., Burrows, J. P., Buchwitz, M., Frerick, J., Noël, S., Rozanov, V. V., Chance, K. V., and Goede, A.: SCIAMACHY mission objectives and measurement modes, J. Atmos. Sci., 56, 127-150, 1999.

Bramstedt, K.: Calculation of SCIAMACHY M-Factors, Technical Note, IFE-SCIA-TN-2007-01-CalcMFactor, Issue: 1, available online at: http://www.iup.uni-bremen.de/sciamachy/mfactors/ mfactor-TN-1-0.pdf, 2008.

Buchwitz, M. and Burrows, J. P.: Retrieval of $\mathrm{CH}_{4}, \mathrm{CO}$, and $\mathrm{CO}_{2}$ total column amounts from SCIAMACHY near-infrared nadir spectra: retrieval algorithm and first results, in: Remote Sensing of Clouds and the Atmosphere VIII, edited by: Schäfer, K. P., Comèron, A., Carleer, M. R., and Picard, R. H., P. SPIE, 5235, 375-388, 2004.

Buchwitz, M., Rozanov, V. V., and Burrows, J. P.: A correlated-k distribution scheme for overlapping gases suitable for retrieval of atmospheric constituents from moderate resolution radiance measurements in the visible/near-infrared spectral region, J. Geophys. Res., 105, 15247-15261, 2000.

Buchwitz, M., de Beek, R., Burrows, J. P., Bovensmann, H., Warneke, T., Notholt, J., Meirink, J. F., Goede, A. P. H., Bergamaschi, P., Körner, S., Heimann, M., and Schulz, A.: Atmospheric methane and carbon dioxide from SCIAMACHY satellite data: initial comparison with chemistry and transport models, Atmos. Chem. Phys., 5, 941-962, doi:10.5194/acp-5-941-2005, 2005a.

Buchwitz, M., de Beek, R., Noël, S., Burrows, J. P., Bovensmann, H., Bremer, H., Bergamaschi, P., Körner, S., and Heimann, M.: Carbon monoxide, methane and carbon dioxide columns retrieved from SCIAMACHY by WFM-DOAS: year 2003 initial data set, Atmos. Chem. Phys., 5, 3313-3329, doi:10.5194/acp-5-3313-2005, 2005 b. 
Buchwitz, M., de Beek, R., Noël, S., Burrows, J. P., Bovensmann, H., Schneising, O., Khlystova, I., Bruns, M., Bremer, H., Bergamaschi, P., Körner, S., and Heimann, M.: Atmospheric carbon gases retrieved from SCIAMACHY by WFM-DOAS: version $0.5 \mathrm{CO}$ and $\mathrm{CH}_{4}$ and impact of calibration improvements on $\mathrm{CO}_{2}$ retrieval, Atmos. Chem. Phys., 6, 2727-2751, doi:10.5194/acp-6-2727-2006, 2006.

Buchwitz, M., Schneising, O., Burrows, J. P., Bovensmann, H., Reuter, M., and Notholt, J.: First direct observation of the atmospheric $\mathrm{CO}_{2}$ year-to-year increase from space, Atmos. Chem. Phys., 7, 4249-4256, doi:10.5194/acp-7-4249-2007, 2007.

Burrows, J. P. and Chance, K. V.: Scanning imaging absorption spectrometer for atmospheric chartography, in: Future European and Japanese Remote Sensing Sensors and Programs, edited by: Slater, P. N., P. SPIE, 1490, 146-155, 1991.

Burrows, J. P., Schneider, W., Geary, J. C., Chance, K. V., Goede, A. P. H., Aarts, H. J. M., de Vries, J., Smorenburg, C., and Visser, H.: Atmospheric remote sensing with SCIAMACHY, Digest of Topical Meeting on Optical Remote Sensing of the Atmosphere, Optical Society of America, Washington DC, USA, 4, 71-74, 1990.

Burrows, J. P., Hölzle, E., Goede, A. P. H., Visser, H., and Fricke, W.: SCIAMACHY - scanning imaging absorption spectrometer for atmospheric chartography, Acta Astronaut., 35, 445-451, 1995.

Chédin, A., Hollingsworth, A., Scott, N. A., Serrar, S., Crevoisier, C., and Armante, R.: Annual and seasonal variations of atmospheric $\mathrm{CO}_{2}, \mathrm{~N}_{2} \mathrm{O}$ and $\mathrm{CO}$ concentrations retrieved from NOAA/TOVS satellite observations, Geophys. Res. Lett., 29, 1269, doi:10.1029/2001GL014082, 2002.

Chédin, A., Serrar, S., Scott, N. A., Crevoisier, C., and Armante, R.: First global measurement of midtropospheric $\mathrm{CO}_{2}$ from NOAA polar satellites: tropical zone, J. Geophys. Res., 108, 4581, doi:10.1029/2003JD003439, 2003.

Crevoisier, C., Chédin, A., Matsueda, H., Machida, T., Armante, R., and Scott, N. A.: First year of upper tropospheric integrated content of $\mathrm{CO}_{2}$ from IASI hyperspectral infrared observations, Atmos. Chem. Phys., 9, 4797-4810, doi:10.5194/acp-9-4797-2009, 2009a.

Crevoisier, C., Nobileau, D., Fiore, A. M., Armante, R., Chédin, A., and Scott, N. A.: Tropospheric methane in the tropics - first year from IASI hyperspectral infrared observations, Atmos. Chem. Phys., 9, 6337-6350, doi:10.5194/acp-9-6337-2009, 2009 b.

Dlugokencky, E. J., Bruhwiler, L., White, J. W. C., Emmons, L. K., Novelli, P. C., Montzka, S. A., Masarie, K. A., Lang, P. M., Crotwell, A. M., Miller, J. B., and Gatti, L. V.: Observational constraints on recent increases in the atmospheric $\mathrm{CH}_{4}$ burden, Geophys. Res. Lett., 36, L18803, doi:10.1029/2009GL039780, 2009.

Dlugokencky, E. J., Lang, P. M., and Masarie, K. A.: Atmospheric methane dry air mole fractions from the NOAA ESRL carbon cycle cooperative global air sampling network, 1983-2009, version: 2010-08-12, available online at: ftp://ftp.cmdl.noaa.gov/ ccg/ch4/flask/event/, last access: 8 September 2010, 2010.

Engelen, R. J. and McNally, A. P.: Estimating atmospheric $\mathrm{CO}_{2}$ from advanced infrared satellite radiances within an operational 4D-Var data assimilation system: results and validation, J. Geophys. Res., 109, D18305, doi:10.1029/2005JD005982, 2005.

Engelen, R. J., Andersson, E., Chevallier, F., Hollingsworth, A.,
Matricardi, M., McNally, A. P., Thépaut, J.-N., and Watts, P. D.: Estimating atmospheric $\mathrm{CO}_{2}$ from advanced infrared satellite radiances within an operational 4D-Var data assimilation system: methodology and first results, J. Geophys. Res., 109, D19309, doi:10.1029/2004JD004777, 2004.

Frankenberg, C., Meirink, J. F., van Weele, M., Platt, U., and Wagner, T.: Assessing methane emissions from global spaceborne observations, Science, 308, 1010-1014, doi:10.1126/science.1106644, 2005.

Frankenberg, C., Meirink, J. F., Bergamaschi, P., Goede, A. P. H., Heimann, M., Körner, S., Platt, U., van Weele, M., and Wagner, T.: Satellite chartography of atmospheric methane from SCIAMACHY onboard ENVISAT: analysis of the years 2003 and 2004, J. Geophys. Res., 111, D07303, doi:10.1029/2005JD006235, 2006.

Frankenberg, C., Warneke, T., Butz, A., Aben, I., Hase, F., Spietz, P., and Brown, L. R.: Pressure broadening in the $2 v_{3}$ band of methane and its implication on atmospheric retrievals, Atmos. Chem. Phys., 8, 5061-5075, doi:10.5194/acp-8-5061-2008, 2008a.

Frankenberg, C., Bergamaschi, P., Butz, A., Houweling, S., Meirink, J. F., Notholt, J., Petersen, A. K., Schrijver, H., Warneke, T., and Aben, I.: Tropical methane emissions: a revised view from SCIAMACHY onboard ENVISAT, Geophys. Res. Lett., 35, L15811, doi:10.1029/2008GL034300, 2008b.

Frankenberg, C., Aben, I., Bergamaschi, P., Dlugokencky, E. J., van Hees, R., Houweling, S., van der Meer, P., Snel, R., and Tol, P.: Global column-averaged methane mixing ratios from 2003 to 2009 as derived from SCIAMACHY: Trends and variability, J. Geophys. Res., 116, D04302, doi:10.1029/2010JD014849, 2011.

Gloudemans, A. M. S., Schrijver, H., Kleipool, Q., van den Broek, M. M. P., Straume, A. G., Lichtenberg, G., van Hees, R. M., Aben, I., and Meirink, J. F.: The impact of SCIAMACHY near-infrared instrument calibration on $\mathrm{CH}_{4}$ and CO total columns, Atmos. Chem. Phys., 5, 2369-2383, doi:10.5194/acp-5-2369-2005, 2005.

Herman, J. R., Bhartia, P. K., Torres, O., Hsu, C., Seftor, C., and Celarier, E.: Global distribution of UV absorbing aerosols from Nimbus7/TOMS data, J. Geophys. Res., 102, 16911-16922, 1997.

Houweling, S., Breon, F.-M., Aben, I., Rödenbeck, C., Gloor, M., Heimann, M., and Ciais, P.: Inverse modeling of $\mathrm{CO}_{2}$ sources and sinks using satellite data: a synthetic inter-comparison of measurement techniques and their performance as a function of space and time, Atmos. Chem. Phys., 4, 523-538, doi:10.5194/acp-4-523-2004, 2004.

Houweling, S., Hartmann, W., Aben, I., Schrijver, H., Skidmore, J., Roelofs, G.-J., and Breon, F.-M.: Evidence of systematic errors in SCIAMACHY-observed $\mathrm{CO}_{2}$ due to aerosols, Atmos. Chem. Phys., 5, 3003-3013, doi:10.5194/acp-5-3003-2005, 2005.

Jenouvrier, A., Daumont, L., Régalia-Jarlot, L., Tyuterev, V. G., Carleer, M., Vandaele, A. C., Mikhailenko, S., and Fally, S.: Fourier transform measurements of water vapor line parameters in the $4200-6600 \mathrm{~cm}^{-1}$ region, J. Quant. Spectrosc. Ra., 105, 326-355, doi:10.1016/j.jqsrt.2006.11.007, 2007.

Keppel-Aleks, G., Wennberg, P. O., and Schneider, T.: Sources of variations in total column carbon dioxide, Atmos. Chem. Phys. Discuss., 10, 30569-30611, doi:10.5194/acpd-10-30569-2010, 
2010.

Krol, M., Houweling, S., Bregman, B., van den Broek, M., Segers, A., van Velthoven, P., Peters, W., Dentener, F., and Bergamaschi, P.: The two-way nested global chemistry-transport zoom model TM5: algorithm and applications, Atmos. Chem. Phys., 5, 417-432, doi:10.5194/acp-5-417-2005, 2005.

Kulawik, S. S., Jones, D. B. A., Nassar, R., Irion, F. W., Worden, J. R., Bowman, K. W., Machida, T., Matsueda, H., Sawa, Y., Biraud, S. C., Fischer, M. L., and Jacobson, A. R.: Characterization of Tropospheric Emission Spectrometer (TES) $\mathrm{CO}_{2}$ for carbon cycle science, Atmos. Chem. Phys., 10, 5601-5623, doi:10.5194/acp-10-5601-2010, 2010.

Lichtenberg, G., Kleipool, Q., Krijger, J. M., van Soest, G., van Hees, R., Tilstra, L. G., Acarreta, J. R., Aben, I., Ahlers, B., Bovensmann, H., Chance, K., Gloudemans, A. M. S., Hoogeveen, R. W. M., Jongma, R. T. N., Noël, S., Piters, A., Schrijver, H., Schrijvers, C., Sioris, C. E., Skupin, J., Slijkhuis, S., Stammes, P. and Wuttke, M.: SCIAMACHY Level 1 data: calibration concept and in-flight calibration, Atmos. Chem. Phys., 6, 5347-5367, doi:10.5194/acp-6-5347-2006, 2006.

Maddy, E. S., Barnet, C. D., Goldberg, M., Sweeney, C., and Liu, X.: $\mathrm{CO}_{2}$ retrievals from the Atmospheric Infrared Sounder: methodology and validation, J. Geophys. Res., 113, D11301, doi:10.1029/2007JD009402, 2008.

Masarie, K. A. and Tans, P. P.: Extension and integration of atmospheric carbon dioxide data into a globally consistent measurement record, J. Geophys. Res., 100, D6, 11593-11610, doi:10.1029/95JD00859, 1995.

Peters, W., Jacobson, A. R., Sweeney, C., Andrews, A. E., Conway, T. J., Masarie, K., Miller, J. B., Bruhwiler, L. M. P., Pétron, G., Hirsch, A. I., Worthy, D. E. J., van der Werf, G. R., Randerson, J. T., Wennberg, P. O., Krol, M. C., and Tans, P. P.: An atmospheric perspective on North American carbon dioxide exchange: CarbonTracker, P. Natl. Acad. Sci. USA, 104, 1892518930, 2007.

Peters, W., Krol, M. C., van der Werf, G. R., Houweling, S., Jones, C. D., Hughes, J., Schaefer, K., Masarie, K. A., Jacobson, A. R., Miller, J. B., Cho, C. H., Ramonet, M., Schmidt, M., Ciattaglia, L., Apadula, F., Heltai, D., Meinhardt, F., di Sarra, A. G., Piacentino, S., Sferlazzo, D., Aalto, T., Hatakka, J., Ström, J., Haszpra, L., Meijer, H. A. J., van der Laan, S., Neubert, R. E. M., Jordan, A., Rodó, X., Morguí, J.A., Vermeulen, A. T., Popa, E., Rozanski, K., Zimnoch, M., Manning, A. C., Leuenberger, M., Uglietti, C., Dolman, A. J., Ciais, P., Heimann, M., and Tans, P. P.: Seven years of recent European net terrestrial carbon dioxide exchange constrained by atmospheric observations, Glob. Change Biol., 16, 1317-1337, doi:10.1111/j.1365-2486.2009.02078.x, 2010.

Rayner, P. J. and O'Brien, D. M.: The utility of remotely sensed $\mathrm{CO}_{2}$ concentration data in surface inversions, Geophys. Res. Lett., 28, 175-178, 2001.

Reuter, M., Buchwitz, M., Schneising, O., Heymann, J., Bovensmann, H., and Burrows, J. P.: A method for improved SCIAMACHY $\mathrm{CO}_{2}$ retrieval in the presence of optically thin clouds, Atmos. Meas. Tech., 3, 209-232, doi:10.5194/amt-3-209-2010, 2010.

Rigby, M., Prinn, R. G., Fraser, P. J., Simmonds, P. G., Langenfelds, R. L., Huang, J., Cunnold, D. M., Steele, L. P., Krummel, P. B., Weiss, R. F., O'Doherty, S., Salameh, P. K.,
Wang, H. J., Harth, C. M., Mühle, J., and Porter, L. W.: Renewed growth of atmospheric methane, Geophys. Res. Lett., 35, L22805, doi:10.1029/2008GL036037, 2008.

Rothman, L. S., Jaquemart, D., Barbe, A., Benner, D. C., Birk, M., Brown, L. R., Carleer, M. R., Chackerian, C., Chance, K., Coudert, L. H., Dana, V., Devi, V. M., Flaud, J.-M., Gamache, R. R., Goldman, A., Hartmann, J.-M., Jucks, K. W., Maki, A. G., Mandin, J.-Y., Massie, S. T., Orphal, J., Perrin, A., Rinsland, C. P., Smith, M. A. H., Tennyson, J., Tolchenov, R. N., Toth, R. A., Vander Auwera, J., Varanasi, P., and Wagner, G.: The HITRAN 2004 molecular spectroscopic database, J. Quant. Spectrosc. Ra., 96, 139-204, doi:10.1016/j.jqsrt.2004.10.008, 2005.

Rothman, L. S., Gordon, I. E., Barbe, A., Benner, D. C., Bernath, P. F., Birk, M., Boudon, V., Brown, L. R., Campargue, A., Champion, J.-P., Chance, K., Coudert, L. H., Dana, V., Devi, V. M., Fally, S., Flaud, J.-M., Gamache, R. R., Goldman, A., Jaquemart, D., Kleiner, I., Lacome, N., Lafferty, W. J., Mandin, J.-Y., Massie, S. T., Mikhailenko, S. N., Miller, C. E., Moazzen-Ahmadi, N., Naumenko, O. V., Nikitin, A. V., Orphal, J., Perevalov, V. I., Perrin, A., Predoi-Cross, A., Rinsland, C. P., Rotger, M., Simeckova, M., Smith, M. A. H., Sung, K., Tashkun, S. A., Tennyson, J., Toth, R. A., Vandaele, A. C., and Auwera, J. V.: The HITRAN 2008 molecular spectroscopic database, J. Quant. Spectrosc. Ra., 110, 533-572, doi:10.1016/j.jqsrt.2009.02.013, 2009.

Schneising, O., Buchwitz, M., Burrows, J. P., Bovensmann, H., Reuter, M., Notholt, J., Macatangay, R., and Warneke, T.: Three years of greenhouse gas column-averaged dry air mole fractions retrieved from satellite - Part 1: Carbon dioxide, Atmos. Chem. Phys., 8, 3827-3853, doi:10.5194/acp-8-3827-2008, 2008.

Schneising, O., Buchwitz, M., Burrows, J. P., Bovensmann, H., Bergamaschi, P., and Peters, W.: Three years of greenhouse gas column-averaged dry air mole fractions retrieved from satellite - Part 2: Methane, Atmos. Chem. Phys., 9, 443-465, doi:10.5194/acp-9-443-2009, 2009.

Solomon, S., Qin, D., Manning, M., Chen, Z., Marquis, M., Averyt, K. B., Tignor, M., and Miller, H. L. (Eds.): Climate Change 2007: The Physical Science Basis, Contribution of Working Group I to the Fourth Assessment Report of the Intergovernmental Panel on Climate Change (IPCC), Cambridge University Press, Cambridge, United Kingdom and New York, NY, USA, 2007.

Stephens, B. B., Gurney, K. R., Tans, P. P., Sweeney, C., Peters, W., Bruhwiler, L., Ciais, P., Ramonet, M., Bousquet, P., Nakazawa, T., Aoki, S., Machida, T., Inoue, G., Vinnichenko, N., Lloyd, J., Jordan, A., Heimann, M., Shibistova, O., Langenfelds, R. L., Steele, L. P., Francey, R. J., and Denning, A. S.: Weak northern and strong tropical land carbon uptake from vertical profiles of atmospheric $\mathrm{CO}_{2}$, Science, 316, 1732-1735, 2007.

Strow, L. L., Hannon, S. E., De-Souza Machado, S., Motteler, H. E., and Tobin, D. C.: Validation of the Atmospheric Infrared Sounder radiative transfer algorithm, J. Geophys. Res., 111, D09S06, doi:10.1029/2005JD006146, 2006.

Tilstra, L. G., de Graaf, M., Aben, I., and Stammes, P.: Analysis of 5 years of SCIAMACHY absorbing aerosol index data, Proceedings ENVISAT Symposium, Montreux, Switzerland, 2327 April 2007, ESA Special Publication SP-636, 2007.

Yang, Z., Washenfelder, R. A., Keppel-Aleks, G., Krakauer, N. Y., 
Randerson, J. T., Tans, P. P., Sweeney, C., and Wennberg, P. O.: New constraints on Northern Hemisphere growing season net flux, Geophys. Res. Lett., 34, L12807, doi:10.1029/2007GL029742, 2007.
Yokota, T., Yoshida, Y., Eguchi, N., Ota, Y., Tanaka, T., Watanabe, H., and Maksyutov, S.: Global concentrations of $\mathrm{CO}_{2}$ and $\mathrm{CH}_{4}$ retrieved from GOSAT: first preliminary results, SOLA, 5, 160-163, doi:10.2151/sola.2009-041, 2009. 